\title{
HIV/AIDS Prevention Guidance for Reproductive Health Professionals in Developing-Country Settings
}

Helen Epstein

Daniel Whelan

Janneke van de Wijgert

Population Council

Purnima Mane

Population Council

Suman Mehta

Follow this and additional works at: https://knowledgecommons.popcouncil.org/departments_sbsr-hiv

Part of the Demography, Population, and Ecology Commons, Family, Life Course, and Society Commons, International Public Health Commons, and the Medicine and Health Commons How does access to this work benefit you? Let us know!

\section{Recommended Citation}

Epstein, Helen, Daniel Whelan, Janneke van de Wijgert, Purnima Mane, and Suman Mehta. 2002. "HIV/ AIDS Prevention Guidance for Reproductive Health Professionals in Developing-Country Settings." New York: Population Council and UNFPA. 


\section{HIV/AIDS Prevention Guidance}

for Reproductive Health Professionals in Developing-Country Settings 


\section{HIV/AIDS Prevention Guidance for Reproductive Health Professionals in Developing-Country Settings}

$5 \bigcirc \underset{19}{Y} E_{2}$ A R R S

P. Population Council

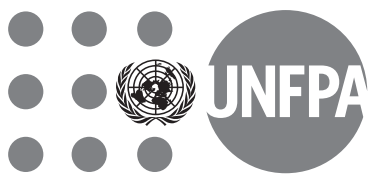

United Nations Population Fund 


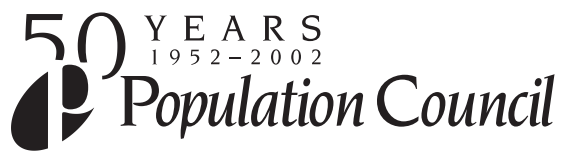

One Dag Hammarskjold Plaza

New York, New York 10017

212-339-0500

fax: 212-755-6052

e-mail: pubinfo@popcouncil.org

www.popcouncil.org

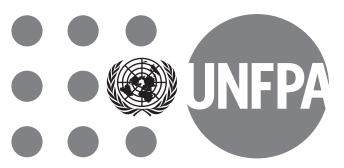

\section{United Nations Population Fund}

220 East 42nd Street

New York, New York 10017

212-297-5273

fax: 212-297-4915

e-mail: hiv@unfpa.org

www.unfpa.org

The Population Council is an international, nonprofit, nongovernmental organization that seeks to improve the well-being and reproductive health of current and future generations around the world and to help achieve a humane, equitable, and sustainable balance between people and resources. The Council conducts biomedical, social science, and public health research and helps build research capacities in developing countries. Established in 1952, the Council is governed by an international board of trustees. Its New York headquarters supports a global network of regional and country offices.

The United Nations Population Fund (UNFPA) supports developing countries, at their request, to improve access to and the quality of reproductive health care, particularly family planning, safe motherhood, and prevention of sexually transmitted infections (STIs) including HIV/AIDS. Priorities include protecting young people, responding to emergencies, and ensuring an adequate supply of condoms and other essentials. The Fund also promotes women's rights, and supports data collection and analysis to help countries achieve sustainable development. About a quarter of all population assistance from donor nations to developing countries is channelled through UNFPA, which works with many government, NGO, and UN partners.

\section{Population Council Library Cataloging-in-Publication Data}

HIV/AIDS prevention guidance for reproductive health professionals in developing-country settings / Helen Epstein et al.- New York : The Population Council and UNFPA, 2002.

$64 \mathrm{p}$.

ISBN 0-87834-110-2

1. AIDS (disease)—Developing countries_Prevention. 2. HIV infections_-Developing countries_Prevention. 3. Reproductive health—Developing countries. I. Population Council. II. United Nations Population Fund. III. Epstein, Helen.

RA 644 .A25 H3485 2002

This document was written by Helen Epstein, Daniel Whelan, Janneke van de Wijgert, Purnima Mane, and Suman Mehta. Helen Epstein and Daniel Whelan are consultants to the Population Council. Janneke van de Wijgert is program associate, and Purnima Mane is vice president and director, International Programs Division, Population Council. Suman Mehta is senior technical officer, Technical and Policy Division, UNFPA.

Copyright (C) 2002 by The Population Council, Inc. and UNFPA

Any part of this publication may be photocopied without permission from the authors or publisher, provided that publication credit is given and that copies are distributed free. Any commercial reproduction requires prior written permission from the Population Council.

Funding for this document was provided by UNFPA (United Nations Population Fund). 


\section{Contents}

Acknowledgments $\quad$ iv

$\begin{array}{ll}\text { Introduction } & 1\end{array}$

Chapter $1 \quad$ Contextual Factors Related to Reproductive Health and HIV/AIDS 3

Chapter 2 HIV Prevention Interventions in Family Planning Settings 9

Chapter $3 \quad$ HIV Prevention Programs for Young People 25

Chapter $4 \quad$ HIV Prevention Among Pregnant Women and Newborns 38

Chapter 5 HIV Prevention Through Management of Reproductive Tract Infections 49

Chapter $6 \quad$ HIV Prevention Among Refugees and Other Displaced Persons 57 


\section{Acknowledgments}

The authors are grateful to the many reproductive health professionals who agreed to be interviewed about the HIV prevention programs they have implemented, including Susan Allen (University of Alabama, United States), Mary Bassett (Rockefeller Foundation, Zimbabwe), Wafutseyoh El-Wambi (Friends of Street Children Project, Uganda), Ron Gray (Johns Hopkins University, United States), Louise Kuhn (Columbia University, United States), Caroline Maposhere (Voices and Choices Project, Zimbabwe), Sostain Moyo (Zimbabwe AIDS Prevention Project, Zimbabwe), Geeta Oodit (International Planned Parenthood Federation, United Kingdom), Mark Stirling (UNICEF, United States), and Johannes van Dam (Population Council, Horizons program, United States).

In August 2001 an early draft of this publication was reviewed at a meeting at the Population Council's office in New Delhi, India. Meeting participants included reproductive health professionals from the South and East Asia office of the Population Council and the UNFPA Technical Advisory Programs in Nepal and Thailand (as well as Helen Epstein and Suman Mehta): Dinesh Agarwal, Monica Bhalla, Celine Costello Daly, Batya Elul, Heiner Grosskurth, M.P.
Gupatha, Vaishali Sharma Mahendra, Anurag Mishra, Anjali Nayyar, Saroj Pachauri, Anil Paul, G. Rangaiyan, K.G. Santhya, Avantika Singh, Farah Usmani, Shalina Verma, and Anjali Widge. The authors would like to thank them for their valuable advice.

We are also grateful to the following experts for their careful review of sections of this publication: Martha Brady, Judith Diers, Fariyal Fikree, Andrew Fisher, Naomi Rutenberg, and Johannes van Dam of the Population Council; Ellen Weiss of the International Center for Research on Women/Horizons program; Maria Jose Alcala, Elizabeth Benomar, Sylvie Cohen, France Donnay, Lindsay Edouard, Francesca Moneti, Julitta Onabanjo, and Akiko Takai of UNFPA; Annette van der Laan of UNESCO, Zimbabwe; and Charles Morrison of Family Health International.

Finally, we extend a special thanks to Rose Maruru (Population Council), who provided invaluable logistical support throughout this project. We also thank Mar Aguilar, Monica Bhalla, Netania Budofsky, Barbara Friedland, and Anil Paul at the Population Council for excellent administrative assistance. Finally, we thank Jared Stamm at the Population Council for editing and production. 


\section{Introduction}

After more than two decades of sustained and expanding HIV/AIDS interventions, it is clear that effective HIV services, programs, and policies for prevention, care, support, treatment, and impact alleviation require multi-sectoral responses from governments, international agencies, and international and national nongovernmental organizations (NGOs). However, organizations and institutions that provide reproductive health services—be they family planning services, antenatal/postpartum clinics, maternal/child health services, clinics for the treatment of sexually transmitted infections (STIs), or any number of integrated service delivery points—stand at the center of HIV/AIDS interventions. While these programs and services are usually geared toward their own particular goals_-providing information about family planning options and technologies to meet the needs of individuals and couples, providing information about and appropriate treatment for STIs, providing information and care for pregnant and postpartum women, and providing services that meet the special needs of youth-it is appropriate and indeed imperative that they be aware of how their particular area of work intersects with the demands of effectively confronting HIV/AIDS at a national level.

It is now widely recognized and acknowledged that effective responses to HIV/AIDS must intervene along a continu- um from prevention of new infections to providing treatment, care, and support for those infected, to mitigating the economic, social, and political impact of those affected by HIV/AIDS. The way in which any particular international agency responds is largely determined by its mandate and area of expertise. The Joint United Nations Programme on HIV/AIDS (UNAIDS) is supported by eight UN co-sponsoring organizations and a Secretariat. ${ }^{1}$ As a UNAIDS co-sponsoring agency, UNFPA plays a central role in spearheading HIV/AIDS interventions as part of its overall stated goal of ensuring universal access to high-quality sexual and reproductive health services to couples and individuals by the year 2015. More specifically, UNFPA's recently published Strategic Guidance on HIV Prevention has emphasized three core areas: preventing HIV infection in young people, strengthening male and female condom programs, and preventing HIV infection in pregnant women. ${ }^{2}$ UNFPA has further stated its commitment to promoting programming and policy activities within an overarching commitment to the goals outlined in the International Conference on Population and Development (ICPD) Programme of Action, as further elaborated at ICPD+5 (United Nations 1999, 1994).

While the integration of information, technologies, and services to respond to

\footnotetext{
1 These are the World Health Organization (WHO), the United Nations Population Fund (UNFPA), the United Nations Children's Fund (UNICEF), the United Nations Development Programme (UNDP), the United Nations Drug Control Program (UNDCP), the United Nations Educational, Scientific and Cultural Organization (UNESCO), the International Labour Organization (ILO), and the World Bank.

2 The UNFPA Strategic Guidance can be accessed at www.unfpa.org/aids/strategic/index.htm.
} 
HIV/AIDS may seem closely related, there are a variety of issues that continue to create obstacles to integration. Among these are the particularly stigmatizing nature of HIV infection and AIDS and discrimination faced by those who are infected or perceived to be infected; sexual practices and identities that remain socially unacceptable; gender roles and relations that make it difficult for women and men to access information, services, and technologies on HIV prevention; reluctance to recognize the special needs and vulnerabilities of young people; and the significant barriers to service delivery created by broader economic, social, cultural, and political factors. Of perhaps greatest concern to reproductive health service providers are the burdens associated with providing additional services and resources needed for facilities, technologies, treatment options, and comprehensive training.

This document is designed to provide an overview of the issues, challenges, and opportunities around integrating a broad range of
HIV/AIDS interventions into existing reproductive and sexual health programs and services, and to provide some practical examples of interventions that have been successful. However, providing comprehensive programmatic or training-related guidelines is beyond its scope. Whenever possible, references are provided to additional sources of information for service providers and program designers.

\section{References}

United Nations. 1994. Report of the International Conference on Population and Development, Cairo, 5-13, September 1994, document E.95.XIII.18. New York: United Nations.

- 1999. "Key actions for the further implementation of the Programme of Action of the International Conference on Population and Development," report of the Ad-Hoc Committee of the Whole of the Twenty-First Special Session of the General Assembly (addendum), document A/S-21/5/Add. 1. New York: United Nations. 


\section{Chapter 1}

\section{Contextual Factors Related to Reproductive Health and HIV/AIDS}

As the HIV/AIDS pandemic enters its third decade, the comparatively hopeful predictions made in the early 1990s that the worst epidemics had reached their plateau have since yielded to the sobering reality that, indeed, the pandemic continues apace-in some cases at alarming rates. Not only is this true in the case of relatively new epicenters such as Eastern Europe and Russia, but it is also true in Africa- a continent that undoubtedly has borne the heaviest burdens of HIV/AIDS since the disease was first identified in the early 1980s. An estimated 5 million people throughout the world became infected in 2001-800,000 of them children (UNAIDS 2002). In the words of Peter Piot, the executive director of UNAIDS, HIV/AIDS is simply "the worst epidemic in human history." While UNAIDS estimates that 40 million people currently live with HIV/AIDS, the number of deaths by the year 2010 is likely to surpass 65 million (UNAIDS 2002). As has been the case since the beginning of the pandemic, the resources needed to successfully meet the challenges of slowing the spread of new infections and effectively treating and caring for those infected or affected by HIV/AIDS far outstrip the resources that governments and donors have made available. The Declaration of Commitment on HIV/AIDS agreed upon by the United Nations General Assembly Special Session on AIDS in 2001 called for $\$ 10$ billion annually to respond to the pan- demic, yet only one-third of that commitment has been met so far (Piot 2002).

Understanding the enormity of the global pandemic of HIV/AIDS is only a first step in mounting an effective set of responses. In reality, the "pandemic" actually comprises a variety of concurrent yet highly varied regional epidemics, each with its own qualities and characteristics. Although more than 70 percent of all infections worldwide occur as a result of heterosexual contact, a variety of other economic, social, and political realities in different parts of the globe determine the extent and severity of regional epidemics. These include demographic factors (such as the age of a population), economic pressures associated with "globalization," migration patterns, patterns of sexual behavior and drug use, and gender roles and relations. The depth and severity of regional epidemics are also associated with poverty, lack of resources, intractable conflicts, and human rights violations.

\section{Sociocultural Norms About Gender Roles and Vulnerability to HIVIAIDS}

As Rao Gupta (2000) points out, "gender" is not synonymous with "sex." It refers to the widely shared expectations and norms within a society about appropriate male and female behaviors, characteristics, and roles. Gender norms are widely reproduced in social institutions, such as schools, workplaces, families, and health systems (Population Council 
2001; Wingood and DiClemente 2000). By defining the societal ideals of feminine and masculine behavior and sexuality, gender norms greatly affect women's and men's access to information and services and how they cope with illness. Gender roles reflect cultural prescriptions for masculinity (and male sexuality) and femininity (and female sexuality). Gender influences what women and men know and how they learn it, their level of communication about sex and behavior within relationships, and their ability to access reproductive health resources, technologies, and services. It is important to remember, however, that in every society there are many forms of masculinity and femininity that vary by social class, ethnicity, sexuality, and age. It is also now recognized that the multiple forms of masculinity and femininity are dynamic, subject to change, and constructed through social interaction (Rivers and Aggleton 2001; Gutmann 1996).

Content and levels of knowledge about sexual risk for $H I V$

A recent analysis of knowledge about HIV/AIDS prevention in 23 developing countries found that levels of knowledge are almost always higher among men than among women, with 75 percent of men, on average, possessing accurate information about HIV/AIDS transmission and prevention as compared to roughly 65 percent of women (Gwatkin and Deveshwar-Bahl 2001). Where women are better informed and have accurate information about sexual risk for HIV, the societal expectation that a woman (especially a young woman) should be naïve makes it difficult for her to demonstrate her knowledge by being proactive in negotiating safer sex. Simultaneously, prevailing norms of masculinity presume men to be more knowledgeable and experienced about sex. This assumption puts men-particularly young men-at risk of infection because such norms prevent them from seeking information or admitting their lack of knowledge about sex or protection. Many men, as a result, have erroneous information about sexual and reproductive health (UNAIDS 1999; Barker and Lowenstein 1997).

\section{Fidelity and multiple partnerships}

Most societies view women's sexual behaviors linked to reproduction as moral and those linked to pleasure as immoral (Rao Gupta and Weiss 1993). In sharp contrast, in many societies it is believed that men's nature dictates that they have variety in sexual partners and that men will inevitably - and shouldseek multiple partners for sexual release (Rao Gupta 2000; Weiss et al. 1996; Mane et al. 1994). Results from sexual behavior studies from around the world indicate that married and single heterosexual men, as well as homosexual and bisexual men, have higher reported rates of partner change than women (Orubuloye et al. 1993; Rao Gupta and Weiss 1993; Sittitrai et al. 1991). This sexual "double standard" compromises the effectiveness of HIV and STI prevention efforts that assume men will be faithful and reduce the number of sexual partners they have (Rao Gupta 2000). Moreover, men's failure to meet certain masculine expectations - for example, providing for the family — can lead them to reclaim self-esteem by complying with other masculine norms, such as engaging in sex with multiple partners (Silberschmidt 2001).

\section{Access to services}

Sociocultural norms that define male and female roles and responsibilities also affect women's and men's access to and use of health services, including reproductive health and HIV/AIDS services. In countries where "son preference" is the norm, in times of scarcity families allocate resources to men 
and boys first and women and girls later or not at all. For example, in Pakistan, lowerincome households seek health care more often for boys than girls and are more likely to use higher-quality providers for boys (Alderman and Gertler 1997). Women themselves perpetuate this pattern because they are socialized to sacrifice their own interests. They often put the health of their children and families first and do not seek medical attention until they are seriously ill (Buvinić and Yudelman 1989).

Women are further constrained from using services where gender norms limit their mobility. Practices such as purdah, common in Hindu and Islamic societies, confine women to their homes and prevent them from traveling to use services unless they are accompanied by an adult male family member. Such practices also demand that health care services employ women caregivers and provide the privacy, modesty, and seclusion necessary for women to feel comfortable using the service (Mehra et al. 1992). Female service providers may be scarce in such settings, further limiting women's access to them.

The barriers that men face in using services are often related to sociocultural norms that ascribe reproductive responsibilities entirely to women and shut men out of parenting or nurturing roles. For example, family planning, antenatal, and child health clinics are typically not designed to reach men or encourage their participation in the care of their partners (see Chapter 2). Because HIV/AIDS information and services are provided primarily in these settings, men are therefore less likely to benefit from them and therefore less likely to be fully informed about HIV/AIDS prevention, care and support, and treatment options (Mane and Aggleton 2001; UNAIDS 2001). This phenomenon has significant implications for men's ability to protect themselves from infection and cope with the epidemic.

\section{Economic Factors That Influence Men's and Women's Reproductive Health}

Over the past several decades, global eco-

nomic growth has noticeably decreased the numbers of individuals living in absolute poverty worldwide. Women's economic status has also shown significant improvement over the last decade. The gender gap in education is significantly lower than in the past, and there are more women earning an income today than ever before. Despite these general trends, however, there is substantial evidence to suggest a number of genderrelated factors have resulted in uneven gains for women as opposed to men. Furthermore, macro-economic policies that are meant to facilitate the entry of countries into global markets (one aspect of "globalization") have led to gender-determined consequences - the "feminization" of poverty for example - that have a differential impact on women's and men's reproductive health. In terms of HIV prevention, these economic factors foster vulnerability to HIV differently for women and men-realities that should inform the design and delivery of reproductive health services, including those for HIV/AIDS.

The commodification of sex and the lack of women's economic leverage in the household Studies from across the developing world indicate that poverty is overwhelmingly the root cause of women's bartering sex for economic gain or survival (UNAIDS 1999). When sex "buys" food, shelter, or safety, it is very difficult to follow prevention messages that call for a reduction in the number of sexual partners. There are a number of "transactional" sexual partnerships that women use as a rational means to make ends meet besides "traditional" commercial sex work. For example, in Haiti, single mothers 
faced with trying to balance the multiple demands of family and economic survival often enter into a series of sexual relationships, called plasaj, in order to obtain food and housing for themselves and their children. Alarmingly, research has shown that women in this setting who have entered a sexual relationship out of economic necessity have increased odds of acquiring syphilis and HIV infection (Fitzgerald et al. 2000).

Women who are economically vulnerable are less able to negotiate the use of a condom or fidelity with a nonmonogamous male partner and less likely to leave relationships that they perceive to be risky because they lack bargaining power and fear abandonment and destitution. Data also show that a number of women in high-risk relationships perceive the short-term costs of leaving a relationship as much greater than the long-term potential health costs (Weiss and Rao Gupta 1998; Heise and Elias 1995; Mane et al. 1994).

Economic factors related to access to and use of health services

Economic factors also affect women's access to and use of services. Economic constraints - such as lack of money to pay for services or transportation or high opportunity costs of lost time-create significant barriers to women's use of health services (Moses et al. 1992; Leslie and Rao Gupta 1989). The workloads of women who live in poverty or in low-income settings make it more difficult for them to take the time to access services. Worldwide, women spend between 10 and 16 hours a day doing housework, collecting water and firewood, caring for children, and producing their family's food-a daily burden of work that is significantly larger than men's (Buvinić and Yudelman 1989). For example, African women perform about 90 percent of the work of hoeing, weeding, processing food, and providing water and firewood; 80 percent of food storage and transport; and 60 percent of harvesting and marketing (World Bank 1989). Taking time to use services is particularly difficult for rural women because they also have to take time to travel to urban areas or village centers where services are located.

Women's economic needs and responsibilities further constrain their use of time. Many women work in insecure jobs with long hours, poor pay, and few or no benefits (United Nations 2000). In such jobs women have little control over the hours or conditions of work, making it difficult for them to take time off. The long hours are added to women's already large burden of domestic work, leaving less time in the day for them to make use of health services. Further, poor pay makes the cost of services more prohibitive for women; and the possibility of losing their insecure and small income, which in many instances is nevertheless critical to a family's survival, makes the opportunity cost of missing work larger for women. Even in families in which income and resources are pooled from multiple individuals, women are still at a disadvantage in accessing funds for health services because families typically allocate resources to men and boys first (Buvinić and Yudelman 1989; International Center for Research on Women 1989).

In summary, sociocultural gender norms reflect how society constructs male and female sexual roles and behaviors that influence their risk for and vulnerability to poor reproductive health generally and HIV infection in particular. These same norms increase women's economic vulnerability and dependence, which in turn increase their vulnerability to being infected, restrict their access to much-needed information and services, and expose them to severe con- 
sequences when infected or affected by HIV/AIDS. For men, gender-related norms and economic need force them to migrate without their families in search of work, creating situations that foster multiple sexual relationships that may lead to HIV infection. Overall, poverty greatly exacerbates both women's and men's vulnerability by restricting access to information and services and making it more difficult to cope with the impact of the epidemic.

\section{References}

Alderman, H. and P. Gertler. 1997. "Family resources and gender differences in human capital investments: The demand for children's medical care in Pakistan," in L. Haddad, J. Hoddinott, and H. Alderman (eds.), Intrahousehold Resource Allocation: Methods, Application, and Policy. Baltimore, MD: Johns Hopkins University Press, pp. 231-248.

Barker, G. and I. Lowenstein. 1997. "Where the boys are: Attitudes related to masculinity, fatherhood, and violence toward women among low-income adolescent and young adult males in Rio de Janeiro, Brazil," Youth and Society 29(2): 166-196.

Buvinić, Mayra and Sally Yudelman. 1989. Women, Poverty and Progress in the Third World. New York: Foreign Policy Association.

Fitzgerald, D.W. et al. 2000. "Economic hardship and sexually transmitted diseases in Haiti's rural Artibonite Valley," American Journal of Tropical Medicine and Hygiene 62(4): 496-501.

Gutmann, Matthew C. 1996. The Meanings of Macho: Being a Man in Mexico City. Berkeley: University of California Press.

Gwatkin, D.R. and G. Deveshwar-Bahl. 2001. Inequalities in Knowledge of HIVIAIDS Prevention: An Overview of Socio-Economic and Gender Differentials in Developing Countries, unpublished draft.

Heise, Lori and Christopher Elias. 1995. "Transforming AIDS prevention to meet women's needs: A focus on developing countries," Social Science and Medicine 40(7): 933-943.

International Center for Research on Women. 1989. Strengthening Women: Health Research Priorities for Women in Developing Countries. Washington, DC: ICRW.

Leslie, J. and G. Rao Gupta. 1989. Utilization of Formal Services for Maternal Nutrition and Health Care in the Third World. Washington, DC: ICRW.

Mane, Purnima and Peter Aggleton 2001. "Gender and HIV/AIDS: What do men have to do with it?" Current Sociology 49(6): 23-37.

Mane, Purnima et al. 1994. "Effective communication between partners: AIDS and risk reduction for women." AIDS 8(suppl 1): S325-S331.

Mehra, Rekha et al. 1992. Engendering Development in Asia and the Near East: A Sourcebook. Washington, DC: ICRW.

Moses, S. et al. 1992. "Impact of user fees on attendance at a referral centre for sexually transmitted diseases," Lancet 340(8817): 463-466.

Orubuloye, I.O., J.C. Caldwell, and P. Caldwell. 1993. "African women's control over their sexuality in an era of AIDS: A study of the Yoruba of Nigeria," Social Science and Medicine 37: 859-872.

Piot, Peter. 2002. "Keeping the promise," opening speech, XIV International AIDS Conference, Barcelona, Spain. 7-12 July.

Population Council. 2001. Power in Sexual Relationships: An Opening Dialogue Among Reproductive Health Professionals. New York: Population Council.

Rao Gupta, Geeta. 2000. "Gender, sexuality, and HIV/AIDS: The what, the why, and the how," plenary address, XIII International AIDS Conference, Durban, South Africa, 9-14 July.

Rao Gupta, Geeta and Ellen Weiss. 1993. Women and AIDS: Developing a New Health Strategy. Washington, DC: ICRW.

Rivers, K. and P. Aggleton. 2001. Men and the HIV Epidemic. New York: United Nations Development Programme. 
Silberschmidt, Margarethe. 2001. "Disempowerment of men in rural and urban East Africa: Implications for male identity and sexual behavior," World Development 29(4): 657-671.

Sittitrai, Werasit et al. 1991. "The survey of partner relations and risk of HIV infection in Thailand," Abstract MD4113. VII International AIDS Conference, Florence, Italy, 16-21 June.

UNAIDS. 1999. Gender and HIVIAIDS: Taking Stock of Research and Programmes. Geneva: UNAIDS.

- 2001. Working with Men for HIV Prevention and Care. Geneva: UNAIDS.

- 2002. Report on the Global HIVIAIDS Epidemic 2002. Geneva: UNAIDS.

United Nations. 2000. The World's Women 2000: Trends and Statistics. New York: United Nations.
Weiss, Ellen and Geeta Rao Gupta. 1998. Bridging the Gap: Addressing Gender and Sexuality in HIV Prevention. Washington, DC: ICRW.

Weiss, Ellen, Daniel Whelan, and Geeta Rao Gupta. 1996. Vulnerability and Opportunity: Adolescents and HIVIAIDS in the Developing World. Washington, DC: ICRW.

Wingood, Gina M. and Ralph J. DiClemente. 2000. "Application of the theory of gender and power to examine HIV-related exposures, risk factors, and effective interventions for women," Health Education and Behavior 27(5): 539-565.

World Bank. 1989. Women in Development: Issues for Economic and Sector Analysis, Policy, Planning, and Research. Washington, DC: World Bank. 


\section{Chapter 2}

\section{HIV Prevention Interventions in Family Planning Settings}

Health providers who work in family planning settings are in a unique position to offer HIV prevention services. Their clients are sexually active people who acknowledge being at risk for unintended pregnancytherefore they may also be at risk for HIV/STIs. There is a natural affinity between the goals of family planning and disease prevention. Both are included in the basic human right to the highest attainable standard of mental and physical healthembodied in a variety of human rights documents, reiterated in the Programmes of Action of ICPD, Beijing, and their respective follow-on implementation processes, and fully endorsed by WHO, the Secretariat of UNAIDS, UNFPA and a number of other UN specialized agencies, and the governing bodies of these organizations. However, there are also a number of differences, which may at times be incompatible between the goals and approaches of family planning and disease prevention programs.

Although results of the same human behavior, pregnancy and HIV/STIs have fundamentally different risk profiles (Cates and Steiner 2002). Risk for pregnancy is determined by when in the cycle and how often sex with any partner occurs-assuming that both the woman and her partner(s) are fertile. Risk for HIV/STIs, on the other hand, is determined primarily by the partners with whom intercourse occurs, the likelihood that these partners are infected, and the frequency of sex with infected partners. Both sets of risks are greater for women than for men. Men are not at risk of unintended pregnancy in the same way as women, because men do not get pregnant. Sexual transmission of HIV and several other STIs appears to be more efficient from men to women than vice versa, partly because semen remains in the vagina for some time after sex. Furthermore, gender dynamics and socioeconomic circumstances often make it more difficult for women than men to modify their risk behaviors. The majority of the world's women want children; they cannot use condoms while trying to conceive. In many cultures, being a mother is considered to be a feminine ideal. In addition, children often provide a social identity for women and status in kinship groups, and they sometimes guarantee economic support from the father (UNAIDS 1999; LeFranc et al. 1996). Reducing the number of sexual partners may not be feasible for those women who, because of limited educational and employment opportunities, are financially dependent on their male partners. Moreover, a significant proportion of monogamous women have male partners who are not monogamous, and these women have little control over their partners' behavior.

Most HIV infections in sub-Saharan Africa occur during heterosexual intercourse between couples (Painter 2001). Even in countries where the prevalence of HIV 
remains relatively low, STIs and other reproductive tract infections (RTIs) often are common (see Chapter 5). In these contexts, many family planning clients may be in need of early detection and treatment of RTIs that can, if untreated, greatly facilitate the transmission of HIV between individuals.

Many attempts have been made to integrate HIV prevention services into family planning settings, which might include providing information about HIV/STIs, incorporating risk assessment for both unintended pregnancy and HIV/STIs into counseling sessions, promoting condoms, and referring clients to other HIV/STI services as needed. Reproductive and sexual health services could also be fully integrated, providing family planning, STI/RTI diagnosis and treatment, voluntary counseling and testing for HIV, antiretroviral therapies for the prevention of mother-to-child transmission of HIV, and antenatal and postpartum services. Services that are fully integrated face a different set of issues than those that provide only family planning and basic HIV prevention. This chapter addresses the full range of issues, however, in order to promote effective integration of services, to provide a blueprint for those services that are considering integration, and to raise the general level of awareness of service providers who may be in a position of having to refer clients to alternative service delivery points outside the scope of their clinic.

Some have raised concerns that incorporating HIV prevention into family planning settings will stigmatize family planning programs, leading to a reduction in the number of family planning clients. So far, however, this has not been observed with any integrated services (WHO 1999a). Of greater concern, perhaps, is that expansion of family planning services inevitably increases staff workload. In addition, resource constraints may mean that the funds needed to train health workers and counselors, procure condoms, and produce information, education, and communication materials are not available. Despite these objections to integration, however, it has become increasingly clear that program success in one area usually translates into better reproductive and sexual health and more effective family planning outcomes overall (WHO 1999a). For example, in many areas family planning programs have been expanding in creative ways to reach members of the community not typically served by these programs, including older men, single adolescents, and young adults of both sexes. These expanded services may improve use of contraception in general, with the result that the number of unwanted pregnancies among young, unmarried people may be reduced.

Contraceptives are often grouped into three categories based on their perfect-use and typical-use effectiveness in preventing pregnancy (Cates and Steiner 2002). The first category includes methods that are highly effective and do not depend on user adherence. This category includes sterilization, hormonal implants and injectables, and intrauterine devices. The second category contains only the oral contraceptive pill. All pills are highly effective if used correctly and consistently, and most pills are relatively forgiving of imperfect use. The third category includes all barrier methods, which are less effective than the methods included in the first two categories, primarily because they require correct and consistent use during every act of intercourse. The third category-as with traditional strategies of pregnancy prevention such as withdrawal and periodic abstinence-is quite unforgiving of imperfect use. Some methods allow couples to prevent pregnancy and HIV infection simultaneously, while others do not. Other 
methods may actually increase a woman's susceptibility to HIV infection under certain circumstances. The following discussion should enable service providers with the appropriate information to provide clients with the most reliable information available.

\section{Methods for Family Planning and Their Relationship to HIV Prevention}

Male condoms

In 2001 the U.S. National Institute of Allergy and Infectious Diseases, the U.S. Centers for Disease Control and Prevention, and the World Health Organization published an extensive review of the literature on the effectiveness of male latex condoms in preventing STIs (U.S. National Institute of Allergy and Infectious Diseases 2001). The review concluded that there is strong evidence that correct and consistent use of male latex condoms prevents HIV infection in men and women and gonorrhea in men; and that there is some evidence that it may prevent gonorrhea in women and chlamydia and trichomoniasis in men and women. The data were considered incomplete for genital ulcer diseases (genital herpes, syphilis, and chancroid) and diseases caused by human papillomaviruses (genital warts and cervical dysplasia or neoplasia) because the pathogens associated with these diseases can infect a wide area of the genitalia that is exposed even when a male condom is used.

Since the earliest days of the HIV pandemic, the use of male condoms has been the staple of HIV prevention efforts. When incorporated into a comprehensive set of prevention messages_-including reducing the number of sexual partners, practicing mutual monogamy, delaying onset and reducing frequency of penetrative sex, and getting treatment for STIs-male condom use has clearly resulted in decreases in the incidence of HIV infection in some settings

\section{RECOMMENDED HIV/STI/RTI SERVICES FOR FIRST-TIME CLIENTS AT FAMILY PLANNING CLINICS}

\section{HIV/STI prevention}

- Information, education, and communication about the risks of HIV infection and infection with other STIs;

- Counseling about dual protection against pregnancy and HIV/STIs;

- Demonstration and provision of male and/or female condoms;

- Encouragement of communication about sex between partners;

- Partner notification where appropriate and if consent is obtained (in the absence of mandatory partner notification laws); and

- Screening for STIs/RTIs.

\section{HIV prevention specifically}

- Onsite voluntary counseling and testing for HIV for those who request it; and

- Referral to appropriate services.

(Sittitrai 2001). Some of these declines have been dramatic, as in the case of Thailand, where an official policy of 100 percent condom use in brothel-based commercial sex settings has yielded impressive results (Sittitrai 2001). In general, over the past 15 years, "condom literacy" among men and women has risen dramatically, and condoms are now more widely available than ever before. However, structured observations in family planning services in many subSaharan African countries have shown that as few as one-quarter of family planning clients receive information on prevention of HIV/STIs (Miller et al. 1998). Furthermore, despite increased availability in most regions of the world, recent analysis of the need for and availability of condoms in sub-Saharan Africa describes a "condom gap"- the difference between the number of condoms needed to provide protection for sexually active couples and the actual number of condoms provided by donor agencies, national governments, and commercial distribution points. The estimated condom gap ranges from 1.9 to 13 billion condoms per year for 
sub-Saharan Africa (Myer et al. 2001;

Shelton and Johnston 2001).

Male condoms can be used for vaginal, oral, and anal sex (although condoms

impregnated with a spermicide are not intended for oral or anal use). In the past few years research and development and better quality control by the condom manufacturing industry have resulted in a male latex condom that is more reliable and safer than ever before (Gilmore 1998). Extra-strong male condoms, intended for use during anal sex, have been available for quite some time. Looking beyond latex, studies are underway to evaluate the effectiveness and acceptability of male condoms with a looser fit made of materials such as polyurethane and styrene ethylene butylene styrene (Finger 2001). Efforts are also underway to design and promote condoms with special designs that may enhance sexual pleasure. It is not yet clear to what degree these kinds of alternative condoms will actually affect consistency of condom use if and when they are available.

Despite the by-now-well-known effectiveness of male latex condoms in prevention of HIV transmission and their increased availability, there are numerous drawbacks associated with relying solely on male condoms within HIV prevention programs. There is evidence to suggest that overall use of male condoms within any given population reaches a certain "plateau." A recent study carried out among adult urban populations in Benin, Cameroon, Kenya, and Zimbabwe found that condom use with nonspousal partners was generally low (21-25 percent for men and 11-24 percent for women). Furthermore, aggregate levels of condom use by city could not be used to discriminate between cities with high and low HIV prevalence (Lagarde et al. 2001). While substantial headway has been made in improving the consistent use of condoms within commercial or casual relationships in some settings (e.g., in Thailand), their introduction into stable or married relationships has proven to be more problematic for a variety of reasons. A commonly cited objection to condom use by both women and men is that condoms interfere with sexual pleasure - and male erection - and create a significant barrier to intimacy between partners (Little et al. 2002; Rhodes and Cusick 2002). Many women and men find discussion of sexual risk and condom use embarrassing, and raising these subjects within a relationship may introduce an element of distrust into that relationship. This is due in part to the association of condoms with casual and commercial sex. Women are often limited in their ability to get their male partners to use a condom because of social, cultural, and economic gender inequalities (see Chapter 1). Some women may even face significant risks, such as violence or abandonment, when they make an attempt to negotiate condom use, or they may be accused of being "loose" or promiscuous. Finally, given a general lack of knowledge about their own sexual and reproductive anatomy, some women have reported being afraid to use condoms, for fear that the condom might become dislodged or stuck in the body (Little et al. 2002; Rhodes and Cusick 2002).

\section{Female condoms}

In order to offer women a barrier method over which they have more control, and in response to other concerns about male condoms, the female condom was developed, approved by the U.S. Food and Drug Administration (FDA), and introduced in 1993. In December 2001, the United States Agency for International Development (USAID) sponsored a technical update on the female condom (USAID 2001). Meeting participants concluded that if the female condom is used correctly and consistently, it 
is as effective as the male condom in preventing HIV/STIs and unwanted pregnancy, but that more research is needed to confirm the method's effectiveness in general populations. In addition, because the outer ring of the female condom partially covers the external genitalia, the female condom may provide greater protection against genital ulcer diseases and human papillomavirus than the male condom.

The female condom has been approved for one-time use only, but in several developing-country settings re-use as a way to reduce cost has been reported. Preliminary data on the safety of re-use indicate that the majority of female condoms still meet quality assurance requirements after repeat use, disinfection, washing, drying, and re-lubrication (Farley et al. 2002). However, excessive or rough handling of female condoms could damage them.

Female condoms were introduced into over 70 countries between 1997 and 2001 (Hatzell and Feldblum 2001). Many of these introduction programs were small pilot activities, but more recently there have been several large-scale efforts. Although use rates of female condoms were relatively high soon after introduction, interest in and consistency of use has tended to drop off over time, probably because the novelty has worn off (Hatzell and Feldblum 2001; Kerrigan et al. 2000; WHO 2000a). Problems with longterm acceptability have also been reported. Research indicates that a significant number of women and men have some difficulty with female condom use, including problems with insertion, discomfort during sex, and excess lubrication (Kerrigan et al. 2000). Furthermore, while the woman usually inserts the female condom, and women have more control over the use of a female as opposed to a male condom, the female condom is visible after insertion and cannot be used without the cooperation of the male partner.

Despite these problems, acceptability studies in sub-Saharan Africa, Asia, Latin America, and the United States have shown that subsets of women in each setting like the female condom and succeed in sustaining its use (Hatzell and Feldblum 2001). Results from a study in Zambia suggested that female condoms might be more acceptable among married couples than male condoms (Musaba et al. 1998). Results from Zimbabwe indicated that sex workers who often experience male condom breakage or have sex with drunk clients preferred female to male condoms (Ray et al. 2001). Several studies have shown that use of the female condom can encourage use of male condoms as well, because it facilitates discussions about safer sex. When faced with the prospect of using a female condom because a female partner insists on it, some men opt to use male condoms instead (Feldblum et al.

2001; Musaba et al. 1998). In any case, the number of protected sexual acts increases when such options are available.

Cervical barriers, spermicides, and microbicides Although female condoms are an important HIV prevention method, they cannot be used without male partner cooperation. Two categories of contraceptive methods that do not necessarily require male partner cooperation, and have been around for decades, are currently being evaluated for their HIV/STI prevention effectiveness: cervical barriers and spermicides.

The best-known cervical barrier is the traditional diaphragm, but several new cervical devices have recently been approved by the FDA or are currently under development (Moench et al. 2001). These include the Leah's shield (a loose-fitting rubber cervical cap with a loop for easy removal), the FemCap (similar to the cervical cap but with 
a brim designed to fit into the vaginal fornices), the SILCS diaphragm (a new onesize-only device expected to be easier to insert and remove), and disposable diaphragms (some of which may come with pre-applied microbicide). Because these devices are worn inside the vagina, they are less obtrusive and less subject to imperfect use than are male and female condoms. They cover the cervix and are therefore likely to protect the cervix from infection by STIs and HIV, but they do not cover the vaginal walls. However, research has shown that the cervix is probably more susceptible to infection with HIV and other STI pathogens than the vagina (Moench et al. 2001). Furthermore, cervical barriers could be used in combination with microbicides that cover parts of the vaginal wall. The combined use of a cervical barrier and a microbicide may provide much better protection than the use of a cervical barrier or microbicide alone. Studies are currently underway to evaluate the effectiveness against HIV and other STIs of cervical barriers alone, or in combination with a microbicide.

Some perceive diaphragms and cervical caps as having low acceptability because only a very small proportion of contracepting women use them. Furthermore, diaphragms have been associated with vaginal anaerobic overgrowth and bladder infections (Cates and Steiner 2002). However, recent studies suggest that acceptability may be much higher if these methods are perceived to provide protection from disease as well as pregnancy, particularly in countries hardest hit by the AIDS epidemic (Bukusi et al. 2002; Padian et al. 2002).

Spermicides have also been available for decades. Almost all currently available spermicides are bio-detergents, and by far the most popular ingredient is nonoxynol-9 $(\mathrm{N}$ 9). N-9-containing products are available worldwide over the counter in a variety of formulations, including gels, creams, suppositories, films, and sponges. Laboratory research conducted in the 1970s and 1980s showed that N-9 could inactivate pathogens such as chlamydia and gonorrhea, and even HIV (WHO 2002). However, recent randomized controlled clinical trials point to a lack of protection against STIs and HIV infection in women using N-9 products without a cervical barrier, and a potential increase in risk for HIV with frequent and multiple daily use (Wilkinson et al. 2002). WHO therefore currently advises not using N-9 for HIV prevention (especially not during anal sex) and contraception if one is at high risk for HIV infection (WHO 2002). Detergents (including N-9) disrupt cell membranes of pathogens and sperm, but also of healthy vaginal epithelial cells, and researchers believe that disruption of the latter may facilitate the transmission of pathogens, including HIV. The failure of N9 to protect women from HIV and other STIs makes the development of non-detergent microbicides that much more urgent.

\section{Hormonal contraceptives}

The next category of family planning methods includes oral contraceptives, injectables, and hormonal implants. Obviously these are not barrier methods, as they do not physically impede the union of sperm and ovum. They tend to be more effective than barrier methods for pregnancy prevention (in particular injectables and hormonal implants that require less in the way of consistent use on the part of the user). However, they do not prevent direct contact of a woman's epithelial tissues with a man's fluids (e.g., semen) or tissues, and therefore cannot prevent the transmission of HIV and other STIs.

There has been some concern that hormonal methods that contain progestinsincluding combined oral contraceptive pills, DMPA and NetEn injectables, and 
Norplant ${ }^{\circledR}$ — could facilitate HIV transmission. This concern arose as the result of a study that found that monkeys given the hormone progesterone were more likely to become infected after vaginal exposure to simian immunodeficiency virus (SIV), a virus closely related to HIV (Smith et al. 2001). The progesterone seemed to make the vaginal lining thinner, thus facilitating transmission of the virus. As for the effects in humans of contraceptives containing progestin, however, more research is needed to examine the relationship between these methods and HIV transmission. The published epidemiological data on the association between combined oral contraceptive pills and DMPA injectables and HIV transmission are inconclusive (Wang et al. 1999; Martin et al. 1998; Mati et al. 1995), while scarce data exist on the relationship between other hormonal methods and HIV transmission. Currently, a large prospective study being conducted in Thailand, Uganda, and Zimbabwe is following 6,200 low-risk, HIV-negative women for up to 24 months to provide data on this critical issue. ${ }^{3}$

\section{Intrauterine devices}

It has long been known that intrauterine devices (IUDs) can facilitate the migration of RTIs from the lower to the upper reproductive tract around the time of insertion (Cates and Steiner 2002). Some have raised concerns that IUDs might increase the risk of female-to-male transmission of HIV, as well as cause dangerous complications in HIVpositive women. However, recent studies suggest that IUDs do not increase cervical shedding of HIV or pose greater risks to HIVpositive women (Richardson et al. 1999).

\section{Sterilization}

Sterilization—including vasectomy—does not provide protection against HIV trans-

\section{A NEW HOPE: MICROBICIDE DEVELOPMENT}

ome promising vaginal microbicides, as well as diaphragms and cer-

vical caps, are now being evaluated for HIV prevention, and it is hoped that new methods will become available in the next five to ten years. Microbicides are chemical or biologic substances capable of blocking infection when used during vaginal (and potentially anal) intercourse. They could come in a gel, cream, suppository, film, or sponge form and would provide women with a method of protection they could initiate themselves. The first microbicide compound studied was nonoxynol-9, which was already available as a spermicide in various formulations for many years. $\mathrm{N}-9$ is a detergent that disrupts the outer membrane of pathogens like HIV, but also that of normal cells. It can therefore cause significant irritation when used frequently. After extensive research by UNAIDS and others, WHO recommends that N-9 no longer be recommended for HIV prevention. However, many other promising products that do not act as detergents but have different mechanisms of action are being developed and evaluated.

Products such as the carrageenan-based Carraguard ${ }^{\mathrm{TM}}$ (developed by the Population Council), Dextrin-2-sulphate, and PRO2000 block attachment of pathogens to the mucosal surface of target cells, thus inhibiting entry of infectious pathogens. Still others, such as PMPA gel, have antiretroviral activity, preventing a virus from entering cells or from replicating once it has entered cells. A microbicide might also maintain high acidity levels in the vagina during intercourse. Examples include Acidform and BufferGel, which enhance the natural defense mechanisms of the vagina against pathogens. Many safety and acceptability studies of these different types of vaginal microbicides have been successfully conducted, and two Phase 3 effectiveness trials are underway, including the Population Council's trial of Carraguard in Botswana and South Africa and the HIV Prevention Trials Network trial (HPTN 035) of BufferGel and PRO2000/5 gel in India, Malawi, South Africa, Tanzania, the United States, Zambia, and Zimbabwe.

For more comprehensive information on current developments concerning microbicides, see van de Wijgert and Coggins 2002, Population Council 2001, and the Web site of the Alliance for Microbicide Development at www.microbicide.org.

mission. In fact, vulnerability to HIV and STIs may increase, as sterilization obviates the need to visit a family planning clinic or center on a regular basis. Thus, the opportunity to reach clients with information and

${ }^{3}$ Family Health International is conducting these studies with support from the U.S. National Institute of Child Health and Human Development. For more information, see Family Health International 2001. 
screening services for STIs is diminished. Service providers should counsel individuals and couples who choose sterilization to continue to visit other sexual and reproductive health services on a regular basis.

\section{Issues Surrounding Dual Protection}

Dual protection is defined as protection against both STIs and unintended pregnancy. Currently it is achieved by consistent use of condoms (male or female) alone or in combination with a highly effective contraceptive and ideally should be backed up by emergency contraception (the use of a high dose of contraceptive hormones within 72 hours of unprotected intercourse to prevent pregnancy) and abortion in the case of method failure (although no backup exists for viral STIs). A less frequently mentioned dual protection strategy is condom use in combination with a second barrier method. It is hoped that the number of available dual protection strategies will increase in the future, when microbicides and cervical barriers are added to the dual protection method mix.

Unfortunately, as described above, currently available methods with the greatest success rate for preventing pregnancy under typical use conditions (sterilization, hormonal methods, and IUDs) provide little to no protection against HIV/STIs. Alternatively, condoms can reduce the risk of many STIs, but are associated with relatively higher pregnancy rates than other contraceptives for most users. This situation poses a dilemma for family planning providers and their clients: Is it better to use two methods, or to rely on condoms for prevention of STIs/HIV and pregnancy?

Several arguments against promoting the use of two methods have been raised (Cates and Steiner 2002). The first concerns the willingness of family planning clients to adopt two methods when in fact it is diffi- cult for them to adopt a single method (although condom use could be focused on potentially infected partners). Second, the adoption of a second method may interfere with consistent use of the first. Third, promoting condoms primarily as a method for disease prevention may stigmatize them, and this, in turn, could inhibit people at risk for HIV/STIs from using condoms. Fourth, a major challenge for service providers is to ensure that infrastructure for expanded service provision is in place, and to change counseling strategies to include dual-method use. Finally, resource constraints - within the family planning setting itself or at the level of the client-may prohibit the use of two methods. Studies examining the success of the dual-method approach are limited and results are often contradictory.

In the absence of evidence-based recommendations, service providers should assist each woman (or couple) in assessing her risk of infection and unintended pregnancy (Cates and Steiner 2002). To achieve dual protection under typical circumstances, tradeoffs must be made. A key factor is a person's likelihood of exposure to infection, which may be assessed either by the prevalence of STIs in the community or by the specific risk behaviors of the person. In settings where exposure to HIV is likely, such as sub-Saharan Africa, condom promotion for prevention of both pregnancy and infection should be emphasized. On the other hand, in settings where unintended pregnancy is the greater concern and cost is less of an issue, such as in many family planning clinics in Europe and the United States, emphasizing a dual-method approach may be appropriate and feasible. The potential consequences of unintended pregnancy and infection should always be considered. An unintended pregnancy, for example, may be acceptable to women if they were using family planning to delay child- 
bearing and an earlier-than-planned pregnancy is acceptable. The availability of backup services-including emergency contraception and safe and affordable abortion-may increase the acceptability of barrier methods as family planning methods. Lastly, the potential consequences of switching methods—or introducing a new method-on the relationship should be considered. A woman who is already using one method of contraception that offers little or no protection against infections may not be able to introduce or switch to condoms without arousing her male partner's suspicions and fears as to the woman's motivations. Doing so may introduce mistrust into the relationship, and may lead to gender-related violence or other negative consequences (see Chapter 1).

These obstacles to enhancing dual-protection strategies for women and men point to the need for family planning services to promote the involvement of men in the design and delivery of these services. The most important approaches should aim at improving men's access to clinic-based services in general. Promotion messages targeted specifically at men might include campaigns that encourage men to use condoms consistently whenever they engage in "outside" sexual relationships. Interventions of this nature should be incorporated within the wider promotion of male responsibility for the health of the wife/partner and children.

\section{Counseling for Family Planning and HIV Prevention}

As mentioned earlier, family planning workers are sometimes the only people in a position to provide reliable and accurate information and counseling to sexually active men and women who need HIV prevention information and technologies in addition to family planning counseling and services. However, as with family planning counseling, address- ing vulnerability to HIV/AIDS and other STIs is not simply a matter of listing abstract risks and behaviors; rather it is about helping clients find healthier, safer ways to live. Effective counseling can help clients and couples to explore, express, understand, and accept feelings and process information in order to foster informed decisionmaking to reduce risk of and vulnerability to STIs. To do this, service providers must go beyond mere risk prevention and may need to address male and female sexuality and the gender power relations that underscore sexual behaviors that contribute to HIV risk and vulnerability. As one staff member in Honduras reported after the service she worked in was expanded to include HIV and RTI counseling: "Before, we used to talk about methods and we'd arrive at an agreement with a client about a method. But now we go much deeper. We ask if she has an infection, we look for risk factors, we can talk about other things such as sexual relations, about her sex life in general, about her partners" (Becker and Leitman 1997). Such discussions help improve the quality of both family planning and HIV prevention services.

Resources and settings for

family planning staff

Acquiring the time, skills, and resources for effective family planning counseling is always a challenge. Integrating HIV prevention into family planning settings increases that challenge considerably. The Population Council studied four projects that combined family planning and HIV prevention in East Africa and found that counselors often failed to ask clients important questions about risk behavior and STI symptoms (Miller et al. 1998). Counselors expressed embarrassment about raising such issues with clients, even though the clients themselves rarely objected to talking about them. In addition, the counselors often assumed their family planning clients 


\section{PROMOTING FAMILY PLANNING AND HIV PREVENTION IN ZAMBIA: THE ZAMBIA- UNIVERSITY OF ALABAMA AT BIRMINGHAM HIV RESEARCH PROJECT}

$\mathrm{I}_{\mathrm{r} e \mathrm{~s}}^{\mathrm{n}}$

$\mathrm{n}$ response to popular demand, an HIV prevention project in Zambia

recently expanded to offer family planning services. Project staff began by offering only condoms, but clients expressed a demand for other contraceptives too, because family planning services in Lusaka were inadequate. Condom use among clients remained high even after other contraceptives were offered. In fact, project staff found that users of other types of contraception were more likely to use condoms as well, and that condom users were twice as likely to start using another form of contraception as well when it was offered to them. "All we had to do to increase contraceptive use was to make it easy to get. That was the secret," said the director of the project.

According to the director, advertising these new services was straightforward. "First we had to educate the community, and we did that by recruiting the first couples who came to the center to be outreach workers. We paid them to go to their friends and spread the word about what we were doing. We also distribute invitations to the center door to door, and about one-third of the people who receive them come in."

were not at high risk of infection, which was not necessarily the case.

Counselor training should include efforts to help trainees overcome their own fears about HIV and prejudices about HIVpositive people. Counselors should understand HIV risk and dual protection strategies, as well as gender-related vulnerabilities that underlie risk and influence their clients' ability to modify risk. Counselors should have access to specific guidelines and checklists to guide their counseling sessions. ${ }^{4}$ Ideally, these guidelines should take local circumstances (HIV/STI prevalence, gender issues, and sexual risk patterns in the community) into account. Counselors should have privacy to counsel clients and adequate time to address both family planning and HIV prevention topics. They should be aware of ethical issues surrounding the protection of client confidentiality in all circumstances. Finally, counselor training must address trainee concerns related to increased job demands that accompany the integration of HIV prevention into family planning work.

\section{Counseling couples}

Research from around the world has shown that despite societal norms that encourage monogamy within marriage and stable, longterm relationships, it is unwise to assume mutual monogamy within all marriages or long-term relationships. While this is true of both men and women, research suggests that men have higher rates of partner change than women, and are more likely to have multiple partners even if they are married or in a longterm relationship (Jenkins et al. 1995;

Orubuloye et al. 1993; Sittitrai et al. 1991). Even when a monogamous woman is aware that her male partner has outside relationships, she may have great difficulty raising concerns about it or negotiating condom use without creating conflict or arousing suspicion about her own behavior. This is especially difficult when a woman who has been using another form of contraception for years decides she wants to introduce condoms into the relationship. One way to address this problem is to encourage greater communication between partners. Couples-counseling, often used among high-prevalence populations, has proven effective in reducing highrisk behavior, particularly among HIV-discordant couples (Painter 2001). Studies also indicate that it is far easier to persuade men to use condoms when couples are counseled together. As one counselor in East Africa told a focus group, "It is easier to counsel a single person, but it is more important to counsel a couple." Although it is not always easy to

\footnotetext{
${ }^{4}$ For information on counseling people who attend antenatal clinics, see WHO 2000b. For information regarding reporting and partner notification guidelines, see WHO 1999b. For a general overview of HIV counseling, see UNAIDS 2002.
} 
persuade men to appear at counseling centers, community education campaigns to encourage male participation may help.

It is important for family planning providers to be aware of the potential obstacles to couples-counseling they may encounter. Women in difficult relationships may seek counseling sessions without their husbands in order to have a safe place to discuss intimate issues and personal challenges in their lives. Family planning providers should be trained to recognize these potential problems and recommend individual counseling for women who may face risks or difficulties as a result of being counseled along with their male partner or husband.

\section{Group counseling}

Group counseling sessions, such as those carried out in International Planned Parenthood Federation (IPPF) clinics in rural Africa and Asia, can help people recognize their own problems and risks by listening to others talk about their experiences. Geeta Oodit of IPPF (in a personal communication with Helen Epstein, August 2001) described these sessions as a way for both individuals and communities to address issues that concern them:

We announce that there is going to be a meeting about health in the community. Men are also encouraged to attend. You have to find out what people want to talk about. Often it's family planning, and we gain their trust by talking about that, but this gives us an opportunity to talk about HIV and STIs as well. These group meetings help break down barriers. Hearing other people talk openly about their problems helps some women open up about their own. For example, some women have learned that their vaginal discharge is not normal, and learning this encourages them to seek help.

\section{TRAINING FAMILY PLANNING COUNSELORS IN HIV PREVENTION: EXAMPLES FROM LATIN AMERICA AND THE CARIBBEAN}

I $\mathrm{n}$ order to talk to clients about their reproductive health, staff must become comfortable with the language of sexuality and learn to overcome their own prejudices against people affected by HIV. In pilot projects in Brazil, Honduras, and Jamaica, training sessions helped staff overcome embarrassment by conducting discussions about sexual acts using both formal language and local slang. Members of the staff were asked to submit anonymous questions about sex so that the group could discuss them. The questions included such topics as masturbation, oral sex, and orgasm. In addition, the sessions involved role-playing, which allowed staff to practice counseling people about sexual abuse, extramarital sex, and homosexuality. Staff were also shown how to use a penis model to demonstrate how to put on condoms, and to demonstrate, in eye-catching ways, the strength of condoms by filling them with water or by putting them on their feet like socks.

Source: Becker and Leitman 1997.

\section{Voluntary HIV Counseling and Testing in Family Planning Settings}

Voluntary HIV counseling and testing programs have become a cornerstone of expanded responses to the HIV/AIDS pandemic. Their importance is based on several factors. First, individuals have a right to know their serostatus in order to protect themselves and others from infection. Second, voluntary counseling and testing may help individuals and couples cope with the anxieties associated with the uncertainty of not knowing their serostatus. Third, early detection of HIV infection allows people to gain access to sources of support and a variety of treatments for HIV infection itself and information on preventing mother-tochild transmission and opportunistic infections associated with HIV and AIDS. Given the increasing pressure from the international community on developed-country governments and pharmaceutical companies to make antiretroviral drugs and other AIDS medications more widely available in devel- 


\section{HIV TEST KITS}

$\mathrm{T}$ he World Health Organization provides guidance on purchasing HIV test kits that are more than 99 percent accurate. All HIV test kits from reputable companies are highly sensitive and specific. Until recently, the standard test kit used in developing countries was the enzyme immunoassay (EIA), but now highly specific and sensitive rapid HIV tests have been developed that can be performed in 30 minutes or less and allow clients to see for themselves the results of the test immediately. This enables health care providers to supply results to patients at the time of testing, potentially increasing the effectiveness of counseling and testing. These tests usually employ viral antigens immobilized in a solid matrix, such as nylon or cellulose membranes, latex, microparticles, or individually packed plastic cards, allowing for individual testing of samples. With the visual development system, rapid tests do not require laboratory equipment-a great advantage for regions where laboratory facilities are scarce. Moreover, with rapid tests a return visit to the clinic is not required. On the other hand, rapid tests can be more expensive than EIAs. Laboratories must thus balance concerns about cost with concerns about ensuring that services rapidly reach the largest number of people. Since EIA tests are carried out on 50 or more samples at one time, laboratories often wait days or even weeks until they have accumulated enough samples. Studies have shown that up to half of all women in developing countries may not return for their EIA results, hence rapid tests may encourage more women to complete the voluntary counseling and testing process and undertake vital prevention activities that can help support and protect themselves and their families. A negative rapid test does not require further testing. A reactive rapid test, on the other hand, must be confirmed by another test of a different type (most commonly an EIA or another rapid test), especially in populations where HIV prevalence is low.

Studies have also found that by far the most expensive component of voluntary counseling and testing services is counseling, not testing, even when the more costly rapid tests are used. The estimated cost of ensuring that adequate numbers of well-trained counselors are available to all women who need them is many times more per client than the rapid test. For these reasons, rapid tests are becoming the norm in many places. Even so, in Lusaka, Zambia, for example, HIV testing services can handle only 50 clients a day, and demand for testing is far greater.

For more information about HIV/AIDS commodities see UNFPA 2002; WHO 2002; and www.who.int/bct/main_areas_of_work/BTS/hiv_ diagnostics/. oping countries, service providers may have more reason to encourage testing and clients more incentives to be tested as treatment options improve. Finally, voluntary counseling and testing has been shown to promote behavior change (de Zoysa et al. 1995). Voluntary HIV counseling and testing is also part of a holistic approach to promoting sexual and reproductive health among individuals and couples and within the community at large. It makes sense, therefore, that such programs be integrated into family planning settings, especially in high-prevalence countries.

In low-prevalence settings, however, resources may not be available for widespread HIV testing. Research in progress suggests that highly sensitive counseling can be as effective as testing at encouraging behavior change (Johannes van Dam, personal communication, August 2001). In such instances, family planning services may be more likely to continue to concentrate on contraceptive provision, while also making women and men more aware of HIV, STIs, and RTIs through counseling services.

Despite the widely acknowledged benefits of voluntary counseling and testing programs, there are also negative implications that family planning service providers should be aware of. Once their serostatus is known, HIV-positive people may be subject to stigma, discrimination, or violence when they disclose their status to others. An HIV-positive test result can also contribute to anxiety and depression. Where health services are generally poor and few treatments are available for HIV-positive people, people may feel the risks of knowing and disclosing their serostatus far outweigh the benefits.

The Population Council's Horizons program evaluated the HIV counseling and testing program in Tanzania and found that men and women sought testing for different 
reasons. Men usually said they were tested to reassure themselves or their partners that they were uninfected, whereas women usually came only if they already suspected they might be HIV-positive because of their own illness or that of a child or spouse. Unlike men, many women said they needed permission from male family members before they could seek testing. The implications of this fact are that women may be expected to disclose their status to family members or others. For women, an HIV-positive result might lead to violence, loss of social support, abandonment, or loss of their children (Maman et al. 2001).

\section{Counseling HIV-positive women and men}

For many people, the prospect of disclosing a positive test result to partners and/or family members is likely to generate feelings of shame and perhaps guilt. Counselors should help clients address their immediate concerns and make decisions about disclosure and sources of support in their families and communities. Referral to HIV support groups, especially groups of people living with HIV/AIDS, is critical. Post-test counseling of HIV-positive people should include information about the stages of HIV infection and other infections and illnesses associated with AIDS in order to raise clients' awareness of their options for treatment. The global movement to secure better and more comprehensive access to antiretroviral therapies means that service providers should be aware of those drugs and proper guidelines for their administration and client adherence to available regimens. ${ }^{5}$ Counselors should also assist clients in ensuring good nutrition and receiving prompt treatment for opportunistic and other illnesses associated with AIDS, especially tuberculosis.

\section{DOMESTIC VIOLENCE AS A RESULT OF HIV DIAGNOSIS}

W

hen women are tested for HIV, counselors must be alert to the risks of abuse and violence if women disclose their status to their families. In addition to endangering the safety of women, coercive or violent behavior prevents negotiation of safer sex and clearly increases risk of infection because of possible damage to tissues. A study carried out by the Population Council's Horizons program in Tanzania found that among women ages $18-29$ years who came for voluntary counseling and testing, those who were HIV-positive were ten times more likely to have been physically abused by their partners in the past three months than women who were HIV-negative. Some women who then disclosed their HIVpositive status found this triggered another episode of violence (Maman et al. 2002). In other studies, between 30 and 80 percent of women who discovered they were HIV-positive did not tell their partners. It is not known whether women who know their status but do not tell their partners practice safer sex. Insisting on condom use might well arouse a partner's suspicions and create the very conflicts the woman sought to avoid in the first place (see Chapter 1 ).

HIV prevention counselors need to question clients who come for HIV testing about violence in their lives and help them find safe ways to disclose their status to partners and family. In some situations it may be safest for women not to disclose their status until circumstances are more favorable.

While some HIV-positive women want to prevent pregnancy to protect their own health and avoid transmitting the virus to a child, counselors are likely to encounter HIV-positive people who, for a variety of reasons, want to have children. In many societies, having children is central to a woman's identity and status. Children also provide hope and purpose in people's lives. As one HIV-positive woman in the United States told a family planning provider, "If I have a child, I will take care of my child and I will be active. I can work because I know I have someone to take care of" (Chan 2001). Some HIV-positive women may also wish to

${ }^{5}$ Service providers should consult WHO/UNAIDS 1998. 
become pregnant to replace a child lost to AIDS. For some women, becoming pregnant may help them allay the suspicions of others that they are HIV-positive. All of these reasons place a substantial burden on family planning counselors to continue to provide clear, accurate information about HIV and AIDS, in order to allow clients to make informed decisions about handling an HIVpositive diagnosis and subsequent family planning. Issues surrounding pregnancy and HIV-seropositivity will be discussed in greater detail in Chapter 4.

\section{References}

Becker, Julie and Elizabeth Leitman. 1997. Introducing Sexuality Within Family Planning: Three Positive Experiences from Latin America and the Caribbean, Quality/Calidad/Qualité no. 8. New York: Population Council.

Bukusi, E.A. et al. 2002. "Acceptability of the diaphragm among women at risk for sexually transmitted diseases in Nairobi, Kenya," Abstract MoPeD3658. XIV International AIDS Conference, Barcelona, Spain, 7-12 July.

Cates, Willard and Markus Steiner. 2002. "Dual protection against unintended pregnancy and sexually transmitted infections: What is the best contraceptive approach?" Sexually Transmitted Diseases 29(3): 168-174.

Chan, J. 2001. "Fertility desires and intentions of HIV-positive men and women," Family Planning Perspectives 33(4): 144-152.

de Zoysa, Isabel et al. 1995. "Role of HIV counseling and testing in changing risk behavior in developing countries," AIDS 9(suppl A): S95-S101.

Family Health International. 2001. "Several counseling options are likely if further research suggests an increased STI risk from hormonal methods," Network 20(4), www.fhi.org/en/fp/fppubs/ network/v20-4/nt2047.html.

Farley, T.M.M., W. Potter, J. Gerofi, and M. Pope. 2002. "Structural integrity of the polyurethane female condom after multiple cycles of disinfection, washing, drying, and re-lubrication," Abstract TuOrD1233. XIV International AIDS Conference, Barcelona, Spain, 7-12 July. Feldblum, P.J. et al. 2001. "Female condom introduction and sexually transmitted infection prevalence: Results of a community intervention trial in Kenya," AIDS 15: 1037-1044.

Finger, W. 2001. "Condom offers STI protection: Condom use should be encouraged among people at risk of HIV and other STIs," Network 20(4): 22-25.

Gilmore, C. 1998. "Recent advances in the research, development and manufacture of latex rubber condoms," in E. McNeill, C. Gilmore, W. Finger et al. (eds.), The Latex Condom: Recent Advances, Future Directions. Research Triangle Park, NC: Family Health International, pp. 36-43.

Hatzell, T. and P.J. Feldblum. 2001. "The female condom: Beyond acceptability to public health impact," Sexually Transmitted Diseases 28(11): 655-657.

Jenkins, Carol et al. 1995. Women and the Risk of AIDS: Study of Sexual and Reproductive Knowledge and Behavior in Papua, New Guinea, Women and AIDS Research Program Research Report Series no. 10. Washington DC: ICRW.

Kerrigan, D. et al. 2000. The Female Condom: Dynamics of Use in Urban Zimbabwe. New York: Population Council.

Lagarde, E. et al. 2001. "Condom use and its association with HIV/sexually transmitted diseases in four urban communities of sub-Saharan Africa," AIDS 15(suppl 4): S71-S78.

LeFranc, E. et al. 1996. "Working women's sexual risk taking in Jamaica," Social Science and Medicine 42(10): 1411-1417.

Little, F. et al. 2002. "Barriers to accessing free condoms of public health facilities across South Africa," South African Medical Journal 92(3): 218-220.

Maman, Suzanne et al. 2001. HIV and Partner Violence: Implications for HIV Voluntary Counseling and Testing Programs in Dar es Salaam, Tanzania. 
Washington, DC: Population Council, Horizons.

. 2002. "HIV-positive women report more lifetime partner violence: Findings from a voluntary counseling and testing clinic in Dar es Salaam, Tanzania," American Journal of Public Health 92: 1331-1337.

Martin, H. et al. 1998. "Hormonal contraception, sexually transmitted diseases, and risk of heterosexual transmission of human immunodeficiency virus type 1, " Journal of Infectious Diseases 178: 1053-1059.

Mati, J.K.G. et al. 1995. "Contraceptive use and the risk of HIV infection in Nairobi, Kenya," International Journal of Gynaecology and Obstetrics 48: 61-67.

Miller, K., H. Jones, and M.C. Horn. 1998. "Indicators of readiness and quality: Basic findings," K. Miller et al. (eds.), ClinicBased Family Planning and Reproductive Health Services in Africa: Findings from Situation Analysis Studies. New York: Population Council, pp. 29-85.

Moench, Thomas R., Tsungai Chipato, and Nancy S. Padian. 2001. "Preventing disease by protecting the cervix: The unexplored promise of internal vaginal barrier devices," AIDS 15: 1595-1602.

Musaba, E. et al. 1998. "Long-term use of the female condom among couples at high risk of human immunodeficiency virus infection in Zambia," Sexually Transmitted Diseases 25: 260-264.

Myer, L., C. Mathews, and F. Little. 2001. "Condom gap in Africa is wider than study suggests," British Medical Journal 323: 937.

Orubuloye, I.O., J.C. Caldwell, and P. Caldwell. 1993. "African women's control over their sexuality in an era of AIDS: A study of the Yoruba of Nigeria," Social Science and Medicine 37: 859-872.

Padian, N. et al. 2002. "Diaphragms are wellaccepted in sexually active Zimbabwean women," Abstract TuOrD1236. XIV International AIDS Conference, Barcelona, Spain, 7-12 July.

Painter, T.M. 2001. "Voluntary counseling and testing for couples: A high leverage intervention for HIV/AIDS prevention in sub-Saharan Africa," Social Science and Medicine 53(11): 1397-1411.

Population Council. 2001. The Case for Microbicides: A Global Priority. New York: Population Council.

Ray, S. et al. 2001. "Female-initiated methods of STI/HIV prevention: Constraints faced by sex workers in use of female and male condoms for safer sex in urban Zimbabwe," Journal of Urban Health 78(4): 581-592.

Rhodes, T. and L. Cusick. 2002. "Accounting for unprotected sex: Stories of agency and acceptability," Social Science and Medicine 55: 155-159.

Richardson, B. et al. 1999. "Effect of intrauterine device use on cervical shedding of HIV-1 DNA," AIDS 13(15): 2091-2097.

Shelton, J. and B. Johnston. 2001. "Condom gap in Africa: Evidence from donor agencies and key informants," British Medical Journal 323: 139.

Sittitrai, Werasit. 2001. HIV Prevention Needs and Successes: A Tale of Three Countries-An Update on HIV Prevention Success in Senegal, Thailand and Uganda. Geneva: UNAIDS.

Sittitrai, Werasit et al. 1991. "The survey of partner relations and risk of HIV infection in Thailand," Abstract MD4113. VII International AIDS Conference, Florence, Italy, 16-21 June.

Smith, S.M., G.B. Baskin, and P.A. Marx. 2001. "Estrogen protects against vaginal transmission of simian immunodeficiency virus," Journal of Infectious Diseases 182(3): 708-715.

UNAIDS. 1999. Gender and HIVIAIDS: Taking Stock of Research and Programmes. Geneva: UNAIDS.

- 2002. HIV Voluntary Counselling and Testing: A Gateway to Prevention and Care. Geneva: UNAIDS, www.unaids. org/publications/documents/health/ counselling/JC729-VCT-Gateway-CSE.pdf.

UNFPA. 2002. "HIV prevention now: Voluntary counselling and testing 
(VCT) for HIV prevention,"

Programme Brief no. 5. Geneva:

UNFPA, www.unfpa.org/aids/

prevention/hivprev5a.htm.

United States Agency for International

Development, Bureau for Africa/Office of Sustainable Development (OSD).

2001. Technical Update on the Female Condom. Washington, DC: USAID.

U.S. National Institute of Allergy and

Infectious Diseases. 2001. Scientific

Evidence on Condom Effectiveness for

Sexually Transmitted Disease Prevention,

summary report of a workshop held in

Herndon, VA, 12-13 June.

van de Wijgert, Janneke and Christiana

Coggins. 2002. "Microbicides to pre-

vent heterosexual transmission of HIV:

Ten years down the road," AIDScience

2(1), www.aidscience.org/articles/ aidscience015.asp.

Wang, C.C., J.K. Kreiss, and M. Reilly. 1999. "Risk of HIV infection in oral contraceptive pill users: A meta-analysis," Journal of Acquired Immune Deficiency Syndromes 21: 51-58.

WHO. 1999a. Integrating STI Management into Family Planning Services: What Are the Benefits? document WHO/RHR/ 99.10. Geneva: WHO.

. 1999b. Questions and Answers on Reporting, Partner Notification and Disclosure of HIV Serostatus andlor
AIDS: Public Health and Human Rights Implications. Geneva: WHO, www.who.int/HIV_AIDS/knowledge/ rptngdiscl.html.

- 2000a. The Female Condom:

A Guide for Planning and Programming. Geneva: WHO.

- 2000b. Voluntary Counseling and Testing for HIV Infection in Antenatal Care: Practical Considerations for Implementation. Geneva: WHO, www.who.int/HIV_AIDS/ knowledge/implvct3.html. . 2002. Sources and Prices of Selected Drugs and Diagnostics for People Living with HIVIAIDS.

Geneva: WHO, www.who.int/ medicines/library/par/ hivrelateddocs/prices-eng.pdf. WHO/UNAIDS. 1998. Nine Guidance

Modules on Antiretroviral Treatments. Geneva: WHO, www.who.int/ hiv_aids/antiretroviral_modules/ indexar.htm.

Wilkinson, D. et al. 2002. "Nonoxynol-9 spermicide for vaginally acquired HIV and other sexually transmitted infections: Systematic review and meta-analysis of randomized controlled trials including over 5,000 women," plenary address at Microbicides 2002, Antwerp, Belgium, 12-15 May. 


\section{Chapter 3}

\section{HIV Prevention Programs for Young People}

UNAIDS estimates that every day around 6,000 people ages 15-24 years contract HIV, and young people now account for nearly half of all new adult infections each year (UNAIDS 2002). In some countries the proportion is even greater, exceeding 60 percent of new infections in sub-Saharan Africa and many parts of Asia (UNAIDS 2002). The risk of and vulnerability to HIV infection among young women are particularly striking: Young women now account for 62 percent of the 11.8 million young people living with HIV/AIDS (UNICEF/UNAIDS/WHO 2002). In Western Kenya, nearly one in four girls 15-19 years old was infected with HIV by the mid-1990s, compared with one in 25 boys in the same age group (Glynn et al. 2001). In Zambia, 16 times as many girls as boys were infected (Glynn et al. 2001). Most important, perhaps, is the fact that only a very small fraction of young people who are infected are even aware of it (UNICEF/ UNAIDS/WHO 2002). The epidemic among young people — which has become far worse than anyone predicted ten years agorepresents one of the most severe challenges to the future health and development of many countries around the world. It requires hard thinking and setting new priorities in HIV prevention and sexual and reproductive health service delivery for the coming decades.

Rates of pregnancy and STIs among adolescents ages 15-19 provide indications of the extent of unprotected sexual activity among young people, and therefore of their vulnerability to HIV/AIDS. Recent data show that more than 25 percent of boys ages 15-19 in Brazil, Hungary, and Kenya report having had sex before the age of 15 (UNICEF/UNAIDS/WHO 2002). In Bangladesh, 88 percent of unmarried boys and 35 percent of unmarried girls living in urban areas have had sex before the age of 18 (UNICEF/UNAIDS/WHO 2002). Males and females under age 25 account for approximately one-third of the 333 million new cases of curable STIs per year (UNICEF/UNAIDS/WHO 2002). Without appropriate treatment for STIs, their risk of contracting HIV increases by as much as three- to fivefold (Wasserheit 1992).

Economic, social, and political conditions in many developing countries create circumstances that make young people particularly vulnerable to HIV infection. Some children may be living on the fringes of society, out of reach of formal school- and community-based services. Street children may be fugitives from violent homes, or orphaned as a result of losing one or both parents to HIV/AIDS. They may be refugees or internally displaced, growing up in urban or periurban slums. They may be children who must work, who are out of school, or who are isolated by prejudice and discrimination because of alternative sexual orientations. Economic circumstances may compel them to sell or barter sex for protection, a meal, or 


\section{A TEN-POINT STRATEGY FOR PREVENTING HIV INFECTION IN YOUNG PEOPLE}

A recent publication released by UNICEF, UNAIDS, and WHO advocates a ten-step strategy for reducing young people's risk for and vulnerability to HIV/AIDS. The steps reinforce each other and can be adopted by countries according to resource availability and the particular epidemiological situation.

1. End the silence, stigma, and shame. Stigma and discrimination prevent young people from seeking out and adopting preventive strategies such as voluntary counseling and testing for HIV and STIs, using condoms, adhering to treatment, or disclosing their HIV status to their partners. National and community leaders must break the silence and challenge stigma and discrimination to create a suitable environment in which prevention initiatives may succeed.

2. Provide young people with knowledge and information. Adolescents need to know the facts about HIV/AIDS before they become sexually active. A basic education of accurate and reliable information about sexuality and HIV-in schools, communities, and via the media-is essential for all children.

\section{Equip young people with the skills to put knowledge into} practice. Life skills-skills in negotiation, conflict resolution, critical thinking, decisionmaking, and communication-are vital for the success of young people's ability to use the knowledge about sexuality and HIV that they have obtained.

4. Provide youth-friendly health services. Services should provide a full range of information, technologies, and services to young people in a welcoming, confidential, conveniently located, and affordable setting. Youth-friendly services can be freestanding or integrated into existing clinics or recreational facilities.

\section{Promote voluntary and confidential HIV counseling and} testing. Studies have shown that young people have a keen interest in knowing their HIV status. Voluntary counseling and testing allows adolescents to evaluate their own behaviors and the consequences. It provides advice and skills for staying HIV-negative, and offers a critically needed point of referral to treatment and sources of support for those who are HIV-positive.

6. Work with young people and promote their participation. Involving young people in prevention efforts educates them about HIV and gives them a sense of responsibility and pride. It also leads to more effective program design and outreach, ensuring that information is communicated in a manner relevant to young people's lives.

7. Engage young people who are living with HIV/AIDS. Young people living with HIV/AIDS are in a unique position to reinforce information about the need to adopt and maintain safe behaviors. They can also help reduce the stigma and discrimination associated with HIV/AIDS, and assist in the development of prevention and support programs for others infected or otherwise affected by HIV/AIDS.

8. Create safe and supportive environments. Even welldesigned interventions will meet with limited success if the intervention environment is hostile or unsupportive of youth. Schools and communities must be unequivocal in condemning sexual coercion and violence, abuse, and exploitation of children and young people. Beyond this, schools and other community organizations can work toward supporting positive norms to reduce the negative gender stereotypes that create vulnerability to HIV among young girls and boys.

\section{Reach out to young people who are most at risk. Those} young people who are at especially high risk for contracting HIV - males who have sex with males, children living on the street, child soldiers, young refugees and internally displaced people, children orphaned by AIDS, young people who use drugs, and children who are sexually exploited - are often on the periphery of society and face enormous challenges in improving their circumstances. They need access to livelihoods training, education, and services to enable them to build a better future.

10. Strengthen partnerships and monitor progress. Meeting the prevention needs of young people requires the efforts of all sectors of society, not just public health. Partnerships must also include governmental and nongovernmental organizations, the private sector, and civil society organizations such as faith-based and community institutions. Reducing the risks and vulnerabilities of young people also requires active monitoring and evaluation of new and existing prevention initiatives in order to establish what works and why, and requires opportunities for new and innovative ways to reach young people with what they need.

Source: UNICEF/UNAIDS/WHO 2002. 
a place to sleep. Sexual interaction may be one of the few opportunities these young people have to experience human warmth and intimacy. An estimated one million children each year are forced into the sex trade, often by their families who are in search of security in an age when globalization is disrupting local economies and family structures. In many parts of the world, the age of marriage for girls is significantly lower than that for men. In addition, husbands may have multiple partners or high rates of partner change, contributing further to young women's risk and vulnerability. Higher frequency of sex within marriage (often "on demand") along with pressure to become pregnant results in women having little room for adopting protective strategies. Drug use may also be part of the "culture" of at-risk youth - a response to feelings of loneliness, boredom, and despair.

The face of HIV/AIDS is thus becoming ever younger, not only in terms of the numbers of people under the age of 25 who are HIV-positive, but also in terms of burdensome economic and social consequences of the pandemic. Taking action to minimize the threat of HIV/AIDS to young people is both a matter of human rights and an absolute necessity for slowing the HIV pandemic. Experience to date shows that interventions for, and in partnership with, young people are among the most effective. Such interventions derive their effectiveness from the fact that young people are less resistant to change than are adults and are generally more willing to examine the social norms that contribute to their risk and vulnerability to HIV.

A number of elements of an expanded response to HIV/AIDS are appropriate for addressing the special needs and vulnerabilities of young people. While the focus of this document up to this point has been on exploring the complexities of integrating HIV prevention interventions within broader reproductive health, family planning, and maternal and child health services and settings, this chapter looks at opportunities to reach young people in diverse settings, citing a wide range of approaches that have been successful.

\section{School-Based HIV Prevention Information, Education, and Skills Development}

The relationship between education and risk of HIV infection is complex. In sub-Saharan Africa, for example, more-developed countries and better-educated people tend to have higher rates of HIV infection. However, while better-educated populations seem to have been more susceptible to HIV early in the epidemic, they also appear to be changing their behaviors more rapidly. In the future, as better-educated groups take steps to protect themselves, it is likely that those at highest risk of acquiring HIV will be people with less education. Therefore, increasing access to education in general, and HIV-related education in particular, should lead more people to change their behaviors to protect themselves from HIV (Hargreaves and Glynn 2002; Gregson et al. 2001). HIV-related education can have an even greater effect on prevention efforts if it is linked with other HIV prevention efforts in the community. Research has shown that education about sexual health does not promote early sexual activity or promiscuity, as some critics contend, but rather delays the initiation of sex and encourages safer sexual behaviors. In 1997 a UNAIDS review of 53 sexual health education programs found that about half had no effect on sexual behavior, while the remaining half either delayed the onset of sexual activity or reduced the rates of unplanned pregnancy and STIs (UNAIDS 1997). 
HIV prevention programs in schools have the potential to reach large numbers of young people before they become sexually active, as well as when they are struggling with their emerging sexual identities, feelings, and relationships. For some young people, school is the most important institution in their experience, and school policies and programs can help many adults as well—including school personnel, parents, and the wider community_cope with HIV. For example, HIV prevention programs can promote tolerance and respect for people infected with HIV/AIDS and can reduce stigmatization of teachers and students affected by the virus and offer them social support (WHO 1999).

Ideally, school-based HIV prevention programs should begin early and be sustained and phased in by age group, from early childhood through adolescence. This is particularly desirable in developing countries where primary school attendance rates may be relatively high but few students reach secondary school. Content appropriate for children should be integrated into life-skills education programs at an early age-before children become sexually active.

Teachers who are appropriately trained and respected by students should be involved in HIV prevention education as much as possible. However, program designers should be aware of the barriers to effective teacher-led sexuality education. For example, many teachers are embarrassed when talking about sex and feel they will lose esteem in their students' eyes if they do so. Sometimes outside specialists can be recruited for this work, but even then teachers should be trained how to identify issues that merit discussion and how to provide referral to further information and services for students.

\section{Innovative Methods for School-Based Programs: Peer-Led Education, Theater, and Role-Plays}

In addition to content, designers and implementers of programs for in-school youth must consider a variety of methods besides formal, lecture-style delivery of information. One method that has met with success in a variety of situations and circumstances is peer-led education. For example, Family Planning Private Sector, an NGO in Kenya, initiated a peer-education project for sexual and reproductive health in collaboration with staff and students in nine colleges. Student representatives and deans from each college were brought together to develop an outline curriculum. Student leaders then established AIDS Awareness Clubs that became the main coordinating bodies for activities. Peer educators organized a variety of activities, including condom distribution and the publication of newsletters. Qualitative evaluation revealed that a number of students were reached through the project, which also increased students' access to services and information. Among the most innovative aspects of the work was the way in which the project team secured the support of the colleges' administration. In addition, success stemmed largely from the fact that young people themselves were involved in all aspects of project design and implementation.

Another successful method is theater and role-plays. In Vanuatu, for example, the Wan Smolbag Theatre developed a popular program for secondary school students that dealt with family planning and infections. The theater group devised sketches showing how such infections as gonorrhea are transmitted through sex. Models of a penis and vagina were put onstage, and actors played the roles of an STI germ, a sperm, and the liquid that carries sperm. The sketches lasted about 30 seconds each, and afterward audi- 


\section{WHAT SHOULD CHILDREN OF DIFFERENT AGES KNOW ABOUT HIV AND OTHER SEXUALLY TRANSMITTED INFECTIONS?}

T he World Health Organization (WHO) and the United Nations Educational, Scientific and Cultural Organization (UNESCO), in their jointly published School Health Education to Prevent AIDS and Sexually Transmitted Diseases (1995), recommended that the content of school-based programs should emphasize life skills and attitudes, as well as biological facts. HIV prevention education must be relevant to the cultural context and should emphasize delaying sexual activity, mutual monogamy, and, where appropriate, condom use. Staff should promote an atmosphere of tolerance toward others, including people infected with HIV. In addition, stereotypes about people with HIV must be overcome. For example, an evaluation of an HIV prevention program sponsored by the Ministry of Health in Bogotá, Colombia found that despite the project's efforts, students still associated HIV/AIDS with sinful behavior and assumed it only affected sex workers, transvestites, and drug users. Young children, preadolescents, and adolescents have different information needs, as outlined below:

Information for young children should help them to:

- know that HIV is a virus that causes a disease called AIDS; HIV cannot be transmitted by casual contact, such as touching and hugging or sharing utensils; and people can be HIV-positive and still look healthy, but when people become sick there is as yet no cure for them;

- accept and not fear people who are HIV-positive or have AIDS;

- understand the concept of socially defined gender roles and the need for males and females to respect one another;

- learn communication skills to resolve conflicts and make healthy decisions to deal with stress; and

- be able to recognize inappropriate sexual advances by older children or adults and report them immediately to adults whom they trust.

Information for preadolescents should teach them to:

- understand the physical changes that take place during adolescence; know what a virus is and how viruses, including HIV, are transmitted; and know about other STIs, their symptoms and consequences, and how to prevent contracting them;

- be aware that they can take actions to avoid disease and pregnancy;

- recognize the social issues, including gender differences, that put people at risk of contracting HIV or other STIs; in addition, boys should understand that responsible sexual behavior and respect for girls is a positive aspect of masculinity;

- show concern for people infected with HIV;

- communicate messages about HIV prevention to their families, peers, and others; they should also know where to find information and services related to sexual health; and

- recognize the importance of resisting peer pressure and acquire basic negotiation skills to help them do this.

Information for adolescents should teach them to:

- recognize the behaviors that place people at risk of contracting HIV or other STIs and how the risk of contracting these infections can be lessened by delaying the initiation of sexual activity and using condoms;

- know how to use a male and female condom, and where to get them;

- know where to go for HIV counseling and testing, if available;

- understand that people do not always behave the way they themselves believe they should;

- have a positive attitude toward HIV prevention and be willing to encourage others to protect themselves; and

- be able to refuse to have sexual intercourse and to negotiate safer alternatives to intercourse.

Curricula for HIV/STI prevention and other health issues can be obtained from governmental or nongovernmental agencies or from teachers' unions. School Health Education to Prevent AIDS and Sexually Transmitted Diseases (WHO/UNESCO 1995) can be obtained through country UNAIDS officials or WHO country and regional offices. 
ence members were invited to explain what had just happened and to ask questions. Members of the Wan Smolbag Theatre have documented improved rates of family planning use and greater understanding of HIV and STIs among their audiences.

\section{Creating a Safe Environment for Successful School-Based Interventions}

Program designers should recognize that not all schools are salutary places for young people-especially young girls. In the regions of the world most seriously affected by HIV/AIDS, epidemiological data reveal that young women are infected in school as a result of unsafe and sometimes coerced sex with classmates or teachers. In Mwanza, Tanzania, for example, parents of children at one school complained that teachers were harassing girls sexually. The school appointed several student guardians - female staff members to whom girls (and boys, if necessary) could turn if they had questions about sexual health or if they were being harassed by a teacher or classmate. The guardians reported allegations to the district authorities, who in turn supported the guardians if they faced threats from men accused of harassing students. Training the guardians to help the girls, moreover, helped the guardians deal with issues of sexual harassment in their own lives. The involvement of other institutions in addition to the schools themselves, including district authorities and the courts, reinforces the importance of prevention for the entire community, and creates the kind of collective will that seems to be required to slow the spread of the virus (UNICEF/UNAIDS/WHO 2002).

Program designers and implementers should also be aware of the consequences the HIV/AIDS epidemic has had on the number of available teachers and on young people's ability to stay in school. In sub-Saharan
Africa, high rates of infection among teachers and students have devastated many schools (UNAIDS 2002). Furthermore, data from studies on girls' educational attainment in agricultural communities indicate that often they are pulled out of school earlier than boys to fulfill household responsibilities, as when adult household members become ill or die as a result of HIV/AIDS (UNAIDS 2002; King and Hill 1993). In addition, as household resources to hire agricultural laborers are depleted, girls are likely to be pulled out of school to fill the gaps in food production (Levine et al. 1996).

Creating a safe environment for young people includes providing them with accurate information that promotes frank, honest discussion about risky sexual behavior. Programs that endorse the importance of virginity for girls do not necessarily protect girls from infection with HIV or STIs. Studies carried out by the International Center for Research on Women found that girls may engage in other forms of risky behavior, such as anal sex, in order to remain, at least technically, virgins. Promoting virginity may even increase girls' risk because it will discourage them from asking for prevention information or gaining access to condoms. Programs that promote either postponement of sex or the practice of protected sex seem to be more successful at encouraging safer behavior than programs that promote abstinence (Weiss et al. 1996).

\section{Community Support for HIV/AIDS and Sexual Health Education}

School-based HIV prevention programs are likely to fail if strong community support for them is lacking. Many communities and governments resist school-based HIV prevention programs, fearing that discussion of sex will encourage immoral behavior.

Community members must therefore be involved in the earliest planning stages, 
through community meetings, parentteacher associations, and religious centers. A school-based HIV-education program in Masaka, Uganda failed because teachers did not feel comfortable talking about sex and condoms in front of students, even though they had been trained to do so. The authors of the study speculate that community attitudes toward the program remained negative, so the program was implemented in a desultory, inconsistent way (Kinsman et al. 2001).

Evidence-based programs - that is, programs that are informed by surveys or operations research and situation analyses - often help convince communities of the necessity of HIV prevention in schools. Such evidence might provide information on HIV and STI prevalence among young people in the area, rates of unwanted pregnancy, and rape and sexual violence.

School health programs need leadership, and the World Health Organization recommends the formation of school health teams - comprising students, teachers, parents, and health workers - to coordinate and monitor all health-promotion activities, including HIV prevention (WHO 1999). School health teams might be supported by community advisory committees, consisting of HIV prevention counselors, community members infected with HIV/AIDS, politicians, sports stars, and others who want to build community support for HIV prevention and help obtain funding for programs. Ideally, each level of community administration would at least be aware of, if not involved in, the planning of a school health education program.

\section{Involving Parents, Teachers, and Community Institutions}

While many young people report that they would prefer to have parents or other family members be primary sources of information and advice about sexuality and sexual health, sometimes the home environment does not support this type of parent-child communication. In addition, adults in the household may not have accurate information about sexual risk in order to properly advise their children. Some young people may find it embarrassing or frightening to discuss intimate issues with their parents; conversely, some parents may prefer to rely on schools to educate their children about matters they themselves find difficult or embarrassing to discuss. Other trusted adults in the community — such as teachers, health workers, and counselors — can help fill the gap if they have a good relationship with the young people around them.

\section{Programs for Out-of-School Young People}

Worldwide, approximately 120 million primary-school-age children are not in schoolwith 40 million of them in sub-Saharan Africa-despite the fact that most countries formally recognize children's right to receive primary-level education free of charge (UNICEF/UNAIDS/WHO 2002). ${ }^{6}$ In some cases, macroeconomic adjustment policies have resulted in a lack of resources for schooling in terms of facilities or the number of available teachers. These realities occasionally coincide with a trend in public school financing whereby a greater share of the costs of education has shifted to families in the

${ }^{6}$ This right has been affirmed in Article 26 of the Universal Declaration of Human Rights; Article 13 of the International Covenant on Economic, Social and Cultural Rights; and Article 28 of the Convention on the Rights of the Child. The latter two treaties spell out specific, legally binding obligations for states that are parties to those treaties. 
form of school fees, making the cost of primary education particularly prohibitive. According to a recent report by OXFAM, declining household income-along with contractions in public provision of educational resources-sometimes results in children being withdrawn from school to reduce pressure on household budgets and generate additional income (Watkins 1999).

Many young people who are out of school are compelled to work to support themselves or their families. Household surveys from a low-income settlement in Lusaka, Zambia found a sharp increase in child labor following structural adjustment, with boys being sent out to earn income directly in the market and girls taking on additional household responsibilities so that adults—especially mothers—could seek income-generating work (Watkins 1999). Children are sometimes compelled to seek work in mines, motorparks, or plantations, and can find themselves in highly vulnerable circumstances where adults can easily take advantage of them-sometimes sexually. A rapid assessment study conducted in several motorparks in Nigeria, for instance, revealed that young boys and girls are susceptible to recruitment into informal sexual networks in which adolescent boys serve as "pimps" for girls who provide casual sex for money or other goods (Babalola 1997). Reaching employed young people with information and access to services and technologies to reduce their risk of and vulnerability to HIV requires interventions that take into account their particular circumstances and the support of their employers.

In Nepal, the Maiti Project has targeted young people subjected to sexual exploitation and abuse, including young women at risk of being sold into prostitution in India. The project has undertaken a range of activities that aim to establish camps in high-risk areas. Each of the camps functions as a shelter for approximately 30 girls who have been rescued from traffickers or who are in danger of being sold. The camps provide education, vocational training, and support and counseling. Project staff have worked closely with colleges, local pressure groups, village leaders, medical offices, lawyers, and police.

Evaluation suggests that the Maiti Project has prevented some girls from being sold into brothels in India. In addition, child traffickers have been exposed and imprisoned as a result of the project's efforts. The project is most remarkable in its integrated approach to meeting the needs of young people and in the ways it takes account of the complex social and economic circumstances of vulnerable young people. ${ }^{7}$

Another young population that is highly vulnerable to HIV and AIDS is street children. Experts believe their numbers are on the rise in the urban slums of the developing world, and that this increase can be attributed to reductions in state spending on education, the growth of urban populations generally, and migration fueled by extensive rural poverty. In addition, the HIV/AIDS pandemic has already created millions of orphans, leaving them on their own or in the care of relatives and neighbors who may find providing this additional care extremely difficult. As with other situations where young people find themselves away from the protection of their families and communities, girls in these circumstances are often compelled to resort to sex work for survival or protection, which places them at very high risk of contracting HIV and STIs. Programs designed to reach street children and address their particular circumstances need to be mounted with the support of wider community organizations that may also have contact with these young

7 More information about the Maiti Project can be found on its Web site, www.maitinepal.org. 
people. Training with police, juvenile justice courts and facilities, and child welfare services is also crucial to the development and sustainability of interventions for reducing vulnerability among this highly at-risk population.

One NGO that has worked with street children in Kampala, Uganda is Friends of Street Children Association (FOCA), which provides food, recreation, schooling, and vocational training to about 200 children living on the streets of Kampala. The children end up on the streets for different reasons. Most have lost at least one parent, often to AIDS, and all come from families too poor to support them and send them to school. One of FOCA's counselors recounted, "It's not easy working with street children, sometimes they insult us, steal our watches and bags, even our shoes." Once on the street, many children fall into a risky life of drug abuse, pickpocketing, petty theft, and sex work, all of which contribute to a very high risk for HIV infection. ${ }^{8}$

Thirty-five of the children who attend FOCA are girls. All are engaged in some kind of sex work, and many have already had children of their own. "They are tougher and harder to help than the boys," says one of the counselors. Street girls are more stigmatized than street boys and are subject to sexual harassment and rape. Many of them move between odd jobs, such as street vending, and enter temporary relationships with men who give them shelter, food, clothes, and other gifts. Half of the babies born to girls at FOCA do not survive their first year.

In order to reduce the risk of HIV infection among street children, FOCA employs about 30 peer educators, all former street children themselves, who distribute condoms, encourage the children to seek voluntary counseling and testing for HIV, and help them obtain prompt treatment for STIs and for opportunistic infections for those already infected. FOCA also provides basic education and vocational training in such skills as tailoring and carpentry. Some graduates have gone on to start their own businesses. One group of children formed an acrobatics team, and another formed a jazz group with donated instruments. The acrobats and musicians earn money by performing at weddings and parties.

\section{Providing Youth-Friendly Reproductive Health Services}

Meeting the needs of sexually active young people is urgent. UNFPA estimates that only 17 percent of these young people use contraceptives. Over 4 million women ages 15-19 years have abortions every year, 40 percent of which are performed under unsafe conditions (UNFPA 2002). Despite the silence and stigma that surround adult attitudes toward young people's sexuality and sexual behavior in most societies, young people want, need, and have a right to reproductive and sexual health services. However, they face many barriers in accessing these resources. Services simply may not exist, and establishing them is strongly opposed by adults. Where they do exist, they may be unaffordable. Stigma may surround youth services, and concerns over lack of confidentiality and disrespectful treatment may inhibit young people from using them.

Reproductive health program designers and service providers can offer services for young people both within and outside the health clinic setting. In the context of HIV/AIDS, access to information and condoms should be made available to young people in places they routinely gather, such as cafés, nightclubs, street vending machines,

${ }^{8}$ For more information on FOCA, contact Friends of Street Children Association, Box 10353, Kampala, Uganda. See also Friends of Street Children Association 2001. 
and vendors. Methods for pregnancy prevention can be made available through pharmacies or through youth support groups, as long as staff are properly trained to provide accurate information and methods to young people. School referrals, workplaces, community or recreation centers, and telephone hotlines are other possible entry points.

Within the clinic setting, young people may need access to a variety of services, including screening and advice on nutrition and other issues related to healthy living; testing for and treatment of STIs, including voluntary HIV counseling and testing; screening, counseling, and referrals for youth-especially young women-who experience violence, sexual abuse, and rape; a range of options for preventing unwanted pregnancy; and antenatal and postpartum services for young women who are pregnant.

The reproductive health needs of young people differ according to their age, living arrangements, education, working status, and, particularly, marital status. Reproductive health service providers should be especially aware of the circumstances of young married women's lives. Early marriage occurs throughout the world, but it is most common in parts of Africa and South Asia. In India and Niger, the percentage of young women married by the age of 18 is 50 and 76 percent, respectively (UNICEF/UNAIDS/WHO 2002). In Nepal, 19 percent of girls are married before they are 15 years old - a number that increases to 60 percent by age 18 (UNICEF/UNAIDS/WHO 2002). Despite the fact that early marriage may indeed mean that young women are more likely to have fewer sexual partners, this fact does not protect them from HIV, because their husbands are usually older and have been sexually active for years. In fact, marriage may actually increase women's vulnerability to HIV infection because of their inability to successfully negotiate condom use or adopt other risk- reduction options. In addition, younger women are more physiologically susceptible to STIs and HIV because of the relative underdevelopment of their reproductive tracts. Men also seek out younger wives, in the hope that they are sexually inexperienced and free from STIs and HIV. Program designers and service providers need to develop and support programs that recognize that younger women may require different interventions than older married women.

\section{Innovative Approaches to Reaching Young People}

Advocacy, information dissemination, and youth empowerment

The Institute of Population Studies at Cayetano Heredia University in Peru designed, implemented, and evaluated a community-based program on sexual and reproductive health for young people in two neighborhoods in Peru (Alarcon and Gonzalez 1996). Program staff sought to mobilize community resources to improve the quality and dissemination of information on related issues; create democratic models for sexual health promotion that respect the rights of young people; empower young people to identify and seek solutions to their sexual and reproductive health problems; and motivate local municipalities, education and health sectors, youth groups, and community-based organizations to direct more resources toward sexual and reproductive health services for young people.

Young people gave positive assessments of the educational workshops because they were participatory, engaging, and focused on their problems and perspectives. Participants were committed to the program strategy, as shown by their level of voluntary involvement as peer promoters. The level of involvement in and support to the project from key members of the community increased significantly over time. The evaluation concluded 
that the project's strategy has high potential

to improve the sexual and reproductive

health of young people and to become established within the community.

Communications campaigns: Radio, print, and television

A media campaign aimed at young people was developed via collaboration between the Dominican Republic's National HIV/STD Prevention Program and 20 governmental and nongovernmental organizations (Academy for Educational Development 2002). Before the media campaign, extensive research-including a knowledge, attitudes, behavior, and practices survey-was carried out to establish a profile of the young people at whom the intervention was aimed. Appropriate messages about HIV/AIDS were then developed and disseminated through radio, television, and print media in three phases. The first phase was designed to increase awareness. The second phase attempted to ensure consistency in messages from different sources and included the production of a manual for teachers and youth workers. The third phase concentrated on making young people aware of how to protect themselves from HIV infection and providing information about where they could access services and support.

An evaluation, which involved focus group discussions with young people, revealed that the messages were perceived as well-targeted, creative, and imaginative. Young people reported that the messages had promoted discussion and helped them reflect on aspects of their behavior. However, young people also reported that more work was needed in order to encourage better communication between parents and children. The overall approach has now been replicated in Guatemala, and other countries in the region are also considering how the method can be adapted for their use.
Telephone hotlines

An AIDS hotline and counseling service evolved out of a trial telephone counseling service established in Egypt by the Ministry of Health (El-Gawhorg 1998). Similarly, UNFPA helped establish telephone hotlines for university students in India. The National AIDS Control Organization (part of the Ministry of Health and Family Welfare of the government of India) established similar hotlines for the general public ("AIDS telephone hotline launched," The Hindu 1997). The hotlines provide a way for people to discuss sexuality, condom use, premarital sex, and homosexuality, all issues that are rarely addressed in public forums. Even with limited advertising, people began to call, and an evident need for the service was identified. The objectives of the hotlines are to provide accurate information about HIV/AIDS to the public, including young people, and to provide confidential and anonymous HIV/AIDS counseling services.

\section{An Integrated Approach for Life-Skills Development and Youth-Friendly Reproductive Health Services}

In Mwanza, Tanzania, young people at risk of HIV and other reproductive health problems have generally lacked access to adequate information and reproductive health care. By age 19, 1 percent of boys and 5 percent of girls are HIV-positive. Since 1999, however, the government of Tanzania, in collaboration with the African Medical and Research Foundation (AMREF), has been offering a range of adolescent sexual health services that are having a dramatic impact on the course of the HIV epidemic in the area and should empower young people to lead healthier lives in general (AMREF 2001). The program, called MEMA kwa Vijana, includes a schoolbased sexual and reproductive health education program led by teachers and peers that makes use of drama, stories, and games. The 
program promotes distribution of condoms to young people by young people themselves. It also provides education both to local health workers (including those involved in STI treatment) to make them more sensitive to the needs of young people and better able to serve those needs, and to parents, teachers, and community leaders about the importance of adolescent reproductive health education.

The program is particularly innovative because it is designed to use a combination of approaches to HIV prevention in a single community, all of which should reinforce each other to promote safer behavior. It is also one of the few HIV prevention programs for young people that will be rigorously evaluated to determine its effect on the spread of HIV. Early results suggest young people's knowledge about HIV has improved dramatically, that health care staff are far more "youth-friendly" than they were before, and, as a consequence, that far more young people seek care from them.

\section{Improving Livelihood Options for Adolescents}

In the context of the HIV/AIDS epidemic and the special needs and vulnerabilities of young people, access to improved livelihood options can reduce the likelihood that young people will need to engage in income-generating activities that put them at greatest risk, especially transactional sexual interactions. Yet adolescents often are not seen as "formal" economic agents, and therefore cannot benefit from programs and policies that expand economic opportunities targeted to adult men and women. Programs created especially for young people help them find formal employment opportunities, provide credit to help them start or expand small-business enterprises, and offer them opportunities to develop basic skills and training for management positions (Rao
Gupta 2002). There is growing recognition that linking such programs with interventions to improve the reproductive health of young people, including HIV/AIDS prevention, furthers the overall goal of addressing the socioeconomic determinants of risk for and vulnerability to HIV/AIDS. Worldwide, there are a range of such programs, yet many are small in scale and limited in scope (Population Council/International Center for Research on Women 2000). Nevertheless, research on the determinants of success of linking such programs should eventually provide reproductive health program designers and policymakers with a clearer set of guidelines for the development of effective programs.

\section{References}

Academy for Educational Development. 2002. AcciónSida, 17 January. Santo Domingo: AED.

African Medical and Research Foundation. 2001. Good Things from Young People: MEMA kwa Vijana, unpublished report. Mwanza, Tanzania: AMREF.

"AIDS telephone hotline launched." 1997. The Hindu, 23 October.

Alarcon, I. and G.F. Gonzalez. 1996. "Attitudes towards sexuality, sexual knowledge and behavior in adolescents in the cities of Lima, Cusco, and Iquitos," report. Lima, Peru: Cayetano Heredia Peruvian University.

Babalola, Stella O. 1997. "Sex-related attitudes and behaviours among a high-risk youth population in Nigeria: A study of four motor parks in Lagos State," unpublished. Lagos: StopAIDS.

El-Gawhorg, K. 1998. "Breaking a social taboo: AIDS hotline in Cairo," Middle East Report (spring).

Friends of Street Children Association. 2001. Baseline Survey Report on Girls That Live and Work on the Streets of Kampala. Kampala, Uganda: Friends of Street Children Association. 
Glynn, J.R., M. Carael, B. Auvert, M. Kahindo, and J. Chege. 2001. "Why do young women have a much higher prevalence of HIV than young men? A study in Kisumu, Kenya and Ndola, Zambia," AIDS 15(suppl 4): S51-S60.

Gregson, S. et al. 2001. "School education and HIV control in sub-Saharan Africa: From discord to harmony?" Journal of International Development 13: 467-485.

Hargreaves, J.R. and J.R. Glynn. 2002. "Educational attainment and HIV-1 infection in developing countries: A systematic review," Tropical Medicine and International Health 7(6): 489-498.

King, E.M. and M.A. Hill. 1993. "Women's education in developing countries: An overview," in E.M. King and M.A. Hill (eds.), Women's Education in Developing Countries: Barriers, Benefits, and Policies. Baltimore: Johns Hopkins University Press, pp. 1-50.

Kinsman, J. et al. 2001. "Evaluation of a comprehensive school-based AIDS education programme in rural Masaka, Uganda," Health Education Research 16(11): 85-100.

Levine, C., D. Michaels, and S.D. Back. 1996. "Orphans of the HIV/AIDS pandemic," in Jonathan Mann and Daniel Tarantola (eds.), AIDS in the World II. New York: Oxford University Press, pp. 278-286.

Population Council/International Center for Research on Women. 2000. Adolescent Girls' Livelihoods-Essential Questions, Essential Tools: A Report on a Workshop. New York and Washington, DC: Population Council and ICRW.

Rao Gupta, Geeta. 2002. Vulnerability and Resilience: Gender and HIVIAIDS in
Latin America and the Caribbean, unpublished draft.

UNAIDS. 1997. Impact of HIV and Sexual Health Education on the Sexual Behavior of Young People: A Review Update, document UNAIDS/97.4. Geneva: UNAIDS.

- 2002. Report on the Global HIVIAIDS Epidemic 2000. Geneva: UNAIDS.

UNFPA. 2002. "Providing services that young people want and need," www. unfpa.org/adolescents/page02.htm.

UNICEF/UNAIDS/WHO. 2002. Young People and HIVIAIDS: Opportunity in Crisis. New York and Geneva: UNICEF/ UNAIDS/WHO.

Wasserheit, Judith N. 1992. "Epidemiological synergy: Interrelationships between human immunodeficiency virus infection and other sexually transmitted diseases," Sexually Transmitted Diseases 19(2): 61-77.

Watkins, Kevin. 1999. Education Now: Break the Cycle of Poverty. London: Oxfam.

Weiss, Ellen, Daniel Whelan, and Geeta Rao Gupta. 1996. Vulnerability and Opportunity: Adolescents and HIVIAIDS in the Developing World. Washington, DC: ICRW.

WHO. 1999. Preventing HIVIAIDS/STI and Related Discrimination: An Important Responsibility of Health Promoting Schools, WHO Information Series on School Health, document 6. Geneva: WHO. WHO/UNESCO. 1995. School Health Education to Prevent AIDS and Sexually Transmitted Diseases: A Resource Package for Curriculum Planners, document WHO/UNESCO/GPA/94/1.2.3. Geneva: WHO. 
Chapter 4

\section{HIV Prevention Among Pregnant Women and Newborns}

Pregnancy and motherhood are among the most important gender roles fulfilled by women throughout the world. It is unfortunate, however, that pregnancy and childbirth may be the only events that bring women into sustained contact with the health care system in any number of developing countries. Maternal and child health $(\mathrm{MCH})$ programs (i.e., antenatal, delivery, and postpartum services) therefore provide a unique opportunity to reach women at risk or otherwise vulnerable to HIV infection with critical information, technologies, and services. As with the basic family planning and reproductive health services discussed earlier, $\mathrm{MCH}$ services can provide pregnant women and new mothers with vital information about HIV/AIDS and its transmission, HIV testing and counseling, and referrals to other services for women regardless of their serostatus.

It is important to note that in almost all parts of the world the majority of pregnant women are HIV-negative (UNAIDS 2002). Even in the urban areas of sub-Saharan Africa where prevalence of HIV infection among pregnant women is the highest in the world, rates of infection remain below 50 percent. This does not detract from the sobering fact that in some of these areas, more than one pregnant woman in three is HIV-positive. Furthermore, research has shown that in the absence of targeted interventions, as many as 40 percent of HIVinfected mothers will transmit the virus to their newborns (WHO 1999). Until recently, the only interventions available to reduce the likelihood of mother-to-child transmission were alterations in infant feeding habits. However, recent breakthroughs in treatment have been shown to dramatically reduce the likelihood of mother-to-child transmission, although these "short-course" regimens themselves have had no measurable impact on slowing the progress of HIV/AIDS in women (WHO 2002a). Many questions about preventing HIV in pregnant women and newborns remain unanswered, but intervention research is ongoing. Service providers must be mindful of the issues related to the integration of new treatments and services into existing programs. In addition, they must be aware of the many contextual factors-including, most importantly, those related to gender-that influence the success of interventions designed to prevent HIV transmission from mother to child and to ensure the highest-quality care available for the continued health of mothers and their newborn children.

\section{Voluntary HIV Counseling and Testing in Antenatal Clinics \\ Chapter 2 described the benefits of voluntary counseling and testing for HIV not only in providing vital information to those who are HIV-positive or -negative, but also in allow- ing people who are HIV-positive to access treatments and services that can assist them in managing and coping with their illness.}


This is particularly important for pregnant women because a diagnosis of HIV infection is the only way to ensure access to the growing number of interventions designed to prevent the transmission of the virus to their newly born children, including access to drug therapies such as zidovudine (AZT) and nevirapine. Another important reason to integrate voluntary counseling and testing programs into antenatal clinics is the opportunity it provides for reaching husbands and male partners of pregnant women. Research has shown that pregnancy can increase men's - and, subsequently, women's - vulnerability to STIs and HIV. Because cultural and other factors and social stigmas limit sexual activity between couples during pregnancy and the postpartum period, men are more likely to seek outside partners during that time (e.g, for data on Nigeria, see Lawoyin and Larsen 2002). Counseling men in the context of expecting a new child provides an opportunity to encourage men to practice safer sex by using condoms and limiting the number of outside partners, or to promote HIV prevention messages that emphasize a man's responsibility to protect the health of his wife/partner and his future family.

Ideally, voluntary counseling and testing in antenatal clinics should be available to all who want it, and increasingly it is becoming standard practice for pregnant women in many parts of the world. However, service providers should be aware of instances in which a male partner coerces his partner into being tested. A pregnant woman who is offered an HIV test as part of antenatal care is often the first in the household to receive a positive test result, and in some cases she is blamed by her male partner for "bringing the virus into the house." Testing both partners simultaneously may help prevent such problems.

\section{BASIC REQUIREMENTS OF HIV PREVENTION PROGRAMS FOR PREGNANT WOMEN}

- Antenatal, delivery, and postpartum care services that are adequate and accessible.

- Information campaigns and community-based efforts to increase acceptance of prevention programs in the community.

- Adequate voluntary counseling and testing services, including reliable tests and trained HIV counselors, for all women who are pregnant or are thinking of becoming pregnant and their male partners.

- Post-test counseling for both HIV-positive and HIV-negative women, as an essential part of all voluntary counseling and testing programs.

- Adequate supplies of male and female condoms.

- Safe delivery services and a referral system in case of complications.

- An affordable, feasible antiretroviral drug regimen that has been proven to reduce the likelihood of mother-to-child-transmission of HIV.

- Counseling about breastfeeding, including information on alternative infant feeding regimens such as infant formula or a short period of exclusive breastfeeding and abrupt weaning for HIV-positive mothers.

- Monitoring to ensure that programs that work in theory do so in practice as well.

- Follow-up of all women, children, and their families to help them deal with issues such as nutrition and pregnancy-related problems.

- Referral to other HIV support and prevention programs and to care and treatment programs for adults with HIV, where available.

There are many ways to encourage women who attend antenatal clinics to enroll in voluntary counseling and testing services. Some projects use videos or group counseling, or they include HIV counseling as part of the midwife's first interview (Susan Allen, personal communication). The goal of such services for pregnant women is to enable those who are HIV-negative to remain so, and those who are positive to make informed decisions about their current pregnancyespecially with regard to the prevention of mother-to-child transmission-and to take care of their own health. Counseling HIVpositive women should also include providing them with information about avoiding reinfection with HIV and prevention of other STIs, and teaching them how to 


\section{REACHING MALE PARTNERS OF PREGNANT WOMEN ENROLLED IN A VOLUNTARY COUNSELING AND TESTING PROGRAM}

\author{
ounselor Sostain Moyo of the Zimbabwe AIDS Prevention Project \\ describes his work:
}

"One of our biggest mistakes at first was not to have male counselors. We are now recruiting men, and it should make a big difference. The point was raised by the husbands of women who came for counseling and testing. They felt we weren't addressing their concerns. But we also realized male counselors can help increase use of prevention services by pregnant women, especially those who feel they cannot take an HIV test without their husband's permission, and they can also make a big contribution to prevention activities in general.

"A sizable number of women are not willing to tell their husbands about their status, because they fear divorce. Many of the women who test positive have not had sex with anyone other than their husbands, so they expect a negative result. For many of those who turn out to be positive, the result is a big surprise. We are trying to find ways to make it easier for women to tell their husbands, but it is hard. In many cases, whoever is tested first is seen as the one who brought the disease. 'Why did you get tested? Why were you expecting that?' the husbands want to know. But since women are counseled in antenatal and family planning clinics, they are often the ones to receive the information first. We have quite a number of pregnant women going through the program who have not told their husbands, but this makes it hard for the women to use protection and plan for the future." obtain care and support. Counselors should assist each woman in determining why she wishes to be tested, yet allow her to make up her own mind about whether and how to proceed.

Pretest counseling for pregnant women should include information about HIV transmission and AIDS, and how to prevent transmission to partners and reduce the risks of transmission to newborns. With regard to the latter, counseling should make it clear that not all babies born to HIV-positive women contract the virus, and that there are ways to reduce the risk of transmission in utero, during delivery, and during nursing (many of which are described in this publication).
Counseling should also make it clear that a woman's exposure to HIV during pregnancy can dramatically increase the likelihood of mother-to-child transmission, because HIV virus levels rise significantly in the days immediately following infection (WHO 1999).

\section{Post-test counseling for HIV-positive pregnant women}

In counseling women who receive a positive HIV test result, service providers should keep a number of important issues in mind. Even though many women who believe they are HIV-positive have their suspicions confirmed by a positive test result, actually receiving the news can come as a shock and result in stress and depression. Counselors therefore need to be careful not to overload newly diagnosed women with information. As Laura Guay, a doctor at Johns Hopkins University who runs an HIV prevention project for pregnant women at Mulago Hospital in Kampala, Uganda puts it, "There is a real risk that a woman will drop out of the program if she is overwhelmed with information at the first visit. After a woman finds she is positive, she tends to shut out everything else for a while, so we just deal with that and give counseling about antiretrovirals, breastfeeding, and so on at a follow-up visit."

Post-test counseling for HIV-positive pregnant women should be carried out in much the same way as it is for any HIVpositive person. Counselors should discuss the patient's immediate concerns, encourage her to ask questions, and help her decide whom she might tell about her status. Counselors should provide information about healthy lifestyles, where to obtain medical care if necessary, and how to contact support groups for people living with HIV/AIDS. Counselors should also explain that while pregnancy does not hasten the 
progression of AIDS, HIV has been associated with such pregnancy complications as premature delivery and spontaneous abortion (WHO 1999). Women should be alert to the signs of these and other complications and should be prepared to seek care immediately if they arise.

HIV-positive women should be referred to programs that aim to prevent mother-tochild transmission with the use of therapeutic regimens (see below). Counselors should also discuss the risks of transmission through breastmilk, alternative feeding options, choices for contraception (see Chapter 2), and the implications of women's HIV status on future reproductive decisions. Studies have found that while some women are more likely to use birth control if they know they are HIV-positive, for many others an HIVpositive diagnosis has no effect on future reproductive decisions, because society places so much emphasis on fertility and motherhood (Feldman et al. 2002). In addition, the promising results of successful mother-tochild transmission prevention interventions have in some cases translated into increases in fertility due to the improved prospects of giving birth to a healthy child.

\section{The effects of HIV and associated illnesses} on pregnancy

Pregnancy does not exacerbate HIV infection or accelerate the progression of AIDS, but HIV infection is associated with greater risk of certain pregnancy complications, including spontaneous abortion, premature birth, and intrauterine growth retardation (WHO 1999). Just as important, while most HIV-positive women are healthy at the time of diagnosis, others may suffer from opportunistic infections such as tuberculosis, other respiratory infections, diarrhea, and candidiasis (vaginal yeast infection or thrush). $\mathrm{MCH}$ counselors are in an ideal position to ensure that clients are properly referred for treatment for these conditions. When counselors discuss treatments for opportunistic infections (although they may not actually administer treatment themselves), they should keep in mind that some drugs, including the tuberculosis medications streptomycin and pyrazinomide, as well as several other antibiotics, should not be used during pregnancy. Furthermore, HIV-positive people should not take certain drugs — such as thioacetazone for the treatment of tuberculosis. HIV-positive pregnant women (and all pregnant women) should be routinely screened for STIs/RTIs, including syphilis and genital herpes—serious infections that may also adversely affect birth outcomes. Routine antenatal care for all pregnant women, including those with HIV, should include treatment for worms, malaria, and other infections when necessary.

Although research suggests that vitamin A supplementation has no effect on motherto-child transmission, the use of multivitamins has been shown to reduce the risks of low birthweight and preterm births, and to increase CD4 cell counts in HIV-positive women (Dreyfuss and Fawzi 2002). While there are at present no official guidelines on provision of vitamins and minerals in antenatal clinics, UNICEF is conducting pilot studies to investigate the feasibility and logistics of making vitamin and mineral supplements, including iron for anemia, a routine part of antenatal care in developing countries.

Finally, the risk of perinatal HIV transmission increases whenever manipulative techniques are used that raise the likelihood of fetal contact with maternal blood. For this reason, invasive procedures such as amniocentesis or chorionic villus sampling should be avoided in women who are known to be HIV-positive. 
The Use of Antiretroviral Drugs in the Prevention of Mother-to-Child Transmission of HIV

The administration of various antiretroviral (ARV) drugs has been shown to reduce the likelihood that an HIV-positive pregnant woman will transmit the virus to her child. Where no drugs are administered and the baby is predominantly breastfed for about 24 months postpartum, the probability of transmission is generally around 30-35 percent (Rutstein 2001). This figure drops to around 20 percent in cases where there is no ARV therapy and the infant is not breastfed by her HIV-positive mother. Research has demonstrated that introduction of ARV drugs decreases the mother-to-child transmission rate by 50 percent (WHO 2002a).

Since 1994 remarkable reductions in pediatric HIV infection rates have been observed in industrialized countries that have adopted the Pediatric AIDS Clinical Trials Group protocol 076, which showed that administration of AZT to women from the 14 th week of pregnancy and during labor and to the newborn decreased the risk of mother-to-child transmission by nearly 70 percent in the absence of breastfeeding (Connor et al. 1994). Unfortunately, issues surrounding the cost and complexities of administering this regimen—such as the fact that many women do not seek antenatal care until well beyond the 14th week of pregnancy-have created significant obstacles to their practical adoption in resource-poor settings.

Nevertheless, a randomized controlled study conducted in Thailand in 1998, which tested a short-course AZT regimen starting from the 36th week of pregnancy, was shown to reduce the risk of transmission of HIV at six months postpartum by 50 percent in a nonbreastfeeding population (Shaffer et al. 1999). Similar trials conducted among breastfeeding women in Burkina Faso and Côte d'Ivoire yielded a 37 percent reduction in mother-to-child transmission (Dabis et al. 1999; Wiktor et al. 1999). Other clinical trials have shown that shortcourse ARV regimens using the combination AZT and lamivudine (Gray 2000) or nevirapine alone (Guay et al. 1999) also substantially decrease the risk of HIV transmission. All of these regimens include administration of ARVs during labor, with varying duration of antenatal and/or postpartum prophylaxis. A single-dose nevirapine regimen provided during labor to the mother and postpartum to the infant has also been shown to be effective-reducing transmission by as much as 42 percent - and thus may be more practical in certain resourcepoor settings (WHO 2001). Subsequent breastfeeding may partially offset this risk reduction, but studies are underway to determine whether daily nevirapine given to breastfeeding mothers and their children for one to six weeks after birth combined with exclusive breastfeeding may reduce or eliminate the risk of transmission during breastfeeding. Although these short-course regimens are not as effective as the longer courses of treatment that are currently the standard in the developed world (which also include replacement feeding and cesarean delivery), they have been deemed feasible for adoption in developing countries. Many such programs are being introduced throughout Africa, Asia, and Latin America and the Caribbean.

\section{Concerns about $A R V$ use for prevention of mother-to-child transmission of HIV}

A number of concerns about the use of antiretroviral drugs during pregnancy have been raised. These include the risk that women may acquire drug resistance if they take nevirapine during pregnancy, that they or their infants may experience toxicity, or that the effects of ARV treatment will be reduced because of HIV transmission during breast- 
feeding. None of the short-course ARV regimens, including administration of nevirapine, has been associated with severe side effects to mothers or infants. Drug-resistant viral strains have been detected in mothers on long-course regimens, and occasionally in mothers taking a short course of treatment, but it is believed that these resistant strains soon die out and are replaced by susceptible ones (Nolan et al. 2002). Research is underway to determine whether resistance acquired during one pregnancy reduces the effect of drugs administered in subsequent pregnancies. While these concerns are important, the World Health Organization recommends that they should not be used as reasons to delay the implementation of programs using ARV drugs to reduce mother-to-child transmission of HIV (WHO 2002a).

\section{HIV Prevention During Labor and Delivery}

Assuming that one-third of children born to HIV-positive mothers will contract HIV in the absence of any kind of intervention, it is estimated that the majority of those infections - 50 percent - will occur during delivery as opposed to in utero (17 percent) or through breastfeeding (33 percent) (UNAIDS 1999). Clearly, all women should have access to safe delivery services, whether or not they are HIV-positive. A trained attendant should be present at all births. Sepsis should be prevented. Attendants should endeavor to prevent vaginal and cervical tears and should avoid performing episiotomies unless absolutely necessary (WHO 1999). These recommendations are particularly crucial for HIV-positive women to lower the overall risk of mother-to-child transmission during labor and delivery.

Unnecessary interventions and procedures should be avoided. The risk of perinatal HIV transmission increases with the duration of membrane rupture, which is a much more

\section{DONATIONS OF NEVIRAPINE TO DEVELOPING COUNTRIES}

R ecently, the pharmaceutical company Boehringer Ingelheim agreed to donate nevirapine for the prevention of perinatal HIV transmission for five years, free of charge, to public maternity services in all developing countries. While this donation offers enormous hope for the prevention of mother-to-child transmission, it relieves only the cost burden of the drug itself, which represents a small proportion of the overall costs of implementing an effective and comprehensive prevention program. In order for health centers to participate in the donation program, the company requires that nevirapine be registered in the country and that participating groups submit a proposal to their ministry of health. In addition, current protocols require adequate testing and counseling services by skilled staff. A trial study is underway in Zambia to determine the cost-effectiveness of administering short-course nevirapine to all women who request it without requiring an HIV test. If successful, such a strategy would only be appropriate in settings where HIV prevalence is high.

important factor than the duration of labor itself (Kuhn et al. 1999). For this reason, membranes should not be ruptured artificially if labor is progressing normally. Also, manipulative procedures—such as attempting to turn breech babies around - should not be performed. Procedures that may break the baby's skin or increases the infant's contact with the mother's blood—such as scalp blood sampling or the application of scalp electrodes—should also be avoided.

Studies have shown that cesarean delivery reduces the likelihood of perinatal transmission of HIV (WHO 1999). However, health facilities in developing countries where HIV prevalence is high are typically poorly equipped, and referral systems are generally weak. Therefore, the number of cesarean deliveries in such settings is low. Even where cesareans are performed, surgical staff may be reluctant to operate on women they know to be HIV-positive for fear of infection. Cesarean deliveries for HIV-positive women are therefore usually only indicated for other medical reasons, such as obstructed labor, and 
not as a public health intervention to reduce perinatal HIV transmission in poor countries. When cesareans are performed, clinicians should administer prophylactic antibiotics to reduce the risk of postpartum infections to which HIV-positive women are more likely to be susceptible (WHO 1999). Finally, a trial in Malawi found that vaginal cleansing with chlorhexidine during delivery reduced the risk of both neonatal and puerperal sepsis, and it seemed to reduce the risk of perinatal HIV transmission, but only in cases where membranes had been ruptured for more than four hours (Taha et al. 1997). Further research on vaginal lavage with chlorhexidine or benzalkonium chloride indicated that it did not have any effect on antenatal transmission (Mandelbrot et al. 2002).

\section{Infant Feeding and HIV Prevention}

It is believed that about 20 percent of children born to HIV-positive women acquire HIV through breastfeeding, depending on duration of breastfeeding and other factors (WHO 2002a). Whereas in developed countries all HIV-positive mothers are advised to use infant formula, women in many developing countries lack access to clean water, with the result that the formula they prepare may transmit deadly infections to babies as well as contribute to malnutrition. Other issues include the social stigma of not breastfeeding and the cost of alternative feeding options. Currently UNICEF and the World Health Organization recommend that health workers counsel each HIV-positive woman about all infant feeding methods, and then allow the mother to make her own informed decision. UNICEF regularly updates training materials for breastfeeding counselors; counselors should therefore try to obtain the latest material from the local UNICEF office. ${ }^{9}$
Exclusive versus mixed infant feeding

In settings where replacement feeding is not practical or can be dangerous, exclusive breastfeeding for a period of three to six months provides immunological and nutritional advantages over replacement feeding, and seems to be associated with only a small risk of HIV transmission to the child (WHO 2002a). Furthermore, in communities where women who replacement feed are stigmatized because it is believed that they may be HIVpositive, exclusive breastfeeding would help women avoid the negative social consequences that might result from replacement feeding.

Recent studies have shown that mixed breast- and replacement feeding should be avoided as much as possible, because it greatly increases the risk that the child will become infected through breastmilk, compared to exclusive replacement feeding or exclusive breastfeeding (WHO 2002a). Nevertheless, mixed feeding is the norm in many places, because exclusive breastfeeding is often difficult, even for very young babies. Women in research studies say that they sometimes experience pressure from family members to give their infants other foods, such as formula or porridge even in the first few months of life (WHO 2002b). In any event, $\mathrm{MCH}$ counselors should advise women that mixed feeding reduces the protective value of breastmilk and is associated with greatly increased risk to the infant of HIV infection, as well as other illnesses.

It is not known why mixed feeding is so much more dangerous than exclusive feeding with either formula or breastmilk. One theory is that infant foods other than breastmilk can cause intestinal infections if they are not prepared properly, and these infections can cause lesions that provide conduits for HIV transmission when the child subsequently

\footnotetext{
${ }^{9}$ For the most recent version see WHO/UNAIDS/UNICEF 2000.
} 
consumes breastmilk. Another theory is that women who breastfeed only on occasion are more prone to breast inflammation (mastitis), which seems to be associated with higher risk of HIV transmission.

Further research is underway to determine the risks and benefits of exclusive breastfeeding for the first three to six months postpartum, and also the best ways to help women in developing countries achieve this (Dabis et al. 2002). One concern is about the weaning period, which may have to be very short in order to avoid prolonged periods of mixed feeding as the child becomes accustomed to other foods. However, very abrupt weaning may be difficult-both physically and emotionally_-for both the mother and the child. Until issues such as this are resolved, breastfeeding counselors face a difficult dilemma—one that requires a careful assessment of each client's particular circumstances. Currently, clinical trials are underway to determine whether postpartum administration of antiretrovirals to HIV-positive mothers and/or their babies improves the safety of breastfeeding. The results of these studies, combined with wider access to these drugs, will influence future recommendations. In any case, project administrators should consult the latest recommendation from UNAIDS and UNICEF.

Another common concern involves the effects of breastfeeding on the overall health of HIV-positive mothers. A recent study from Kenya found that HIV-positive women who breastfed exclusively had a significantly higher risk of death during the first two years postpartum than HIV-positive women who used formula exclusively (Nduati et al. 2001). This has raised concern that the nutritional status of some HIV-positive women may not be adequate to sustain prolonged breastfeeding, and that this may accelerate the progression of AIDS in some cases. A similar study in
South Africa, however, showed no significant correlation between breastfeeding and premature maternal mortality from HIV/AIDS

(Coutsoudis et al. 2001). However, since the two studies are not entirely comparable or considered to be definitive, further studies are underway to investigate the effects of breastfeeding on maternal mortality due to HIV/AIDS.

While breastfeeding is often the preferred method of feeding in most developing countries, health workers must avoid making recommendations that might not be in the best interests of the mother and child based on their own biased preference for breastfeeding. Counselors should provide all available information accurately and responsibly so that women can make informed decisions based on their own circumstances. Further, health workers should support those decisions and, in the event a new mother chooses not to breastfeed, provide access to cheap or free infant formula and clean water. Researchers at the University of Natal, South Africa found that the best way to help women make informed choices about infant feeding was to clearly explain the risks and benefits of each method rather than issue directives about what to do. As a result, a significant number of women chose to breast- or bottlefeed exclusively (Bland et al. 2002).

\section{What About the Mothers (and Fathers)?}

Most of this chapter has been devoted to the prevention of mother-to-child transmission of HIV. Critics have pointed out—and rightfully so- that the imperative of preventing pediatric HIV infection, while not necessarily at the expense of mothers, infringes on women's dignity and rights by treating them only instrumentally in order to "save" children. Furthermore, all who work in reproductive health settings, from the national to the local level, are in a position to advocate for one of 
the most basic human rights, namely universal access to treatments, including antiretrovirals, that impede the onset of AIDS.

However, a basic fact that has been known for some time bears repeating in the context of HIV/AIDS: Even when prevention of HIV among newborns is successful, the likelihood that a child will survive to the age of five when her mother, or father, or both are lost to AIDS is quite low. Program planners and policymakers must therefore strive to do everything possible within resource-poor settings to ensure the health and longevity of HIV-positive mothers, fathers, and all adults.

These concerns should encourage program staff to improve health care for all HIVpositive people, through advocacy and by solidifying the referral links between prevention programs for pregnant women, the public health care system, and networks of people living with HIV/AIDS. Even where the lack of resources is an obstacle to ARV therapy, prevention and care programs in developing countries can offer an HIV-positive woman vital counseling and, at the very least, nutritional support and assistance in planning for the children she has, as well as treatment for the many opportunistic infections associated with HIV.

\section{"MTCT-Plus"}

Programs that offer pregnant HIV-positive women ARV drugs to protect their unborn children offer little help to women suffering from AIDS. With these ethical concerns in mind, a group of foundations working through a Secretariat established at Columbia University recently created a new program to help women and babies affected by HIV. MTCT-Plus, which is providing its first grants in 2002, is designed to link mother-to-child transmission (MTCT) prevention efforts to HIV/AIDS treatment initiatives in order to increase the chances of survival of infected mothers who are identi- fied in MTCT prevention programs. An essential care package for mothers would include treatment for opportunistic infections such as tuberculosis, AIDS-associated fungal infections, STIs, and others illnesses. The package would also include ARV therapy throughout the life of the mother, child, and, when possible, the entire family when certain clinical criteria were met.

At first, MTCT-Plus programs will be tested in countries where HIV prevalence in the general adult population is at least 5 percent and where programs using ARV drugs to prevent mother-to-child transmission are already in place and functioning reasonably well. Such programs should be able to offer women voluntary counseling and testing for HIV, as well as standard antenatal care. In addition, a laboratory capable of measuring levels of CD4 lymphocytes will be necessary for MTCT-Plus. Questions remain about how best to implement the program, what the costs will be, and whether such a program can be sustained. Pilot projects should help resolve these issues and identify best practices. MTCT-Plus could provide a means for extending better AIDS patient care to whole communities, not just to pregnant women and their babies. Eventually, treatment ideally will be offered to women's partners and to other infected children in the family.

Programs to integrate HIV prevention into maternal health services are still at an early stage. ARV drugs for the prevention of mother-to-child HIV transmission are available in only a small number of hospitals and clinics in the developing world, but already these pilot programs are demonstrating that there are substantial costs in addition to the cost of the drugs themselves. Additional resources are necessary to carry out effective, sensitive counseling, including increased space, training, and staff salaries. In addition, antenatal programs in many developing coun- 
tries are inadequate. Malaria prophylaxis, blood grouping, hemoglobin tests, and iron and folate supplementation should all be routine in antenatal care, but they seldom are in many resource-poor countries. The incorporation of new services into already existing programs comes with certain costs-and these cannot be overlooked. There is little doubt that antenatal care has been less than ideal in most settings for decades. However, anecdotal evidence suggests that the introduction of interventions to prevent mother-to-child transmission has boosted morale among service providers by empowering them with the appropriate informational and therapeutic tools to address the consequences of HIV/AIDS in their communities. Program designers and policymakers should consider the potential positive impact of integration on the overall quality of antenatal care services, rather than assume that the introduction of MTCT prevention programs will weaken already resource-constrained services.

Finally, it is important to note that HIV prevention programs for pregnant women will achieve little if women at risk of HIV feel stigmatized and believe that they lack control over their reproductive lives. In highprevalence regions, all pregnant womenwhether HIV-positive or -negative-will need to decide whether or not to take an HIV test and whom to tell about the results. If they are HIV-positive, they must decide whether to take antiretroviral drugs, if available, or undergo other treatments to prevent transmission to their babies. They have to make choices about the best options for feeding their infants. They also must make informed decisions about future childbearing. Very often, pressure from partners, families, and communities will prevent women from making these decisions on their own. Preventing HIV transmission involves far more than providing information and condoms. It also involves helping women recognize their own vulnerability, which often has its roots in gender-related discrimination they experience in their productive as well as reproductive lives. Therefore, an overarching concern of all health workers involved in HIV prevention programs must be to empower women and, if possible, improve their status in society through advocacy designed to protect and promote the rights - especially reproductive and sexual health rights — of all women.

\section{References}

Bland, R.M. et al. 2002. "Breastfeeding practices in an area of high HIV prevalence in rural South Africa," Acta Paediatrica 91(66): 704-711.

Connor, E.M. et al. 1994. "Reduction of maternal-infant transmission of human immunodeficiency virus type 1 with zidovudine treatment," New England Journal of Medicine 331(18): 1173-1180.

Coutsoudis, A., H. Coovadia, K. Pillay, and L. Kuhn. 2001. "Are HIV-infected women who breastfeed at increased risk of mortality?” AIDS 15: 653-655.

Dabis, F. et al. 1999. "6-month efficacy, tolerance, and acceptability of a short regimen of oral zidovudine to reduce vertical transmission of HIV in breastfed children in Côte d'Ivoire and Burkina Faso: A double-blind placebo-controlled multicentre trial," Lancet 353: 786-792.

_. 2002. "Improving child health: The role of research," British Medical Journal 324(7351): 1444-1447.

Dreyfuss, M.L. and W.W. Fawzi. 2002. "Micronutrients and vertical transmission of HIV-1," American Journal of Clinical Nutrition 75(6): 959-970.

Feldman, R., J. Manchester, and C. Maposhere. 2002. Positive Women: Voices and Choices: Zimbabwe Report. London: International Community of Women Living with HIV/AIDS.

Gray, G. 2000. "Early and late efficacy of three short ZDV/3TC combination regimens to prevent mother-to-child trans- 
mission of HIV-1," Abstract LbOr5. XIII International AIDS Conference, Durban, South Africa, 9-14 July.

Guay, L.A. et al. 1999. "Intrapartum and neonatal single-dose nevirapine compared with zidovudine for prevention of mother-to-child transmission of HIV-1 in Kampala, Uganda: HIVNET 012 randomised trial," Lancet 354: 795-802.

Kuhn, L. et al. 1999. "Distinct risk factors for intrauterine and intrapartum human immunodeficiency virus transmission and consequences for disease progression in infected children," Journal of Infectious Diseases 179(1): 52-58.

Lawoyin, T.O. and U. Larsen. 2002. "Male sexual behaviour during wife's pregnancy and postpartum abstinence period in Oyo State, Nigeria," Journal of Biosocial Science 34(1): 51-63.

Mandelbrot, L. et al. 2002. "15-month follow-up of African children following vaginal cleansing with leuzalkonium chloride of their HIV-infected mothers during late pregnancy and delivery," Sexually Transmitted Infections 78(4): 267-270.

Nduati, R. et al. 2001. "Effect of breastfeeding on mortality among HIV-1 infected women: A randomised trial," Lancet 357: 1651-1655.

Nolan, M., M.G. Fowler, and L.N. Mofeson. 2002. "Antiretroviral prophylaxis of perinatal HIV transmission and the potential impact of antiretroviral resistance," Journal of Acquired Immune Deficiency Syndromes 30(2): 216-229.

Rutstein, R.M. 2001. "Prevention of perinatal HIV infection," Current Opinion in Pediatrics 13(5): 408-416.

Shaffer, N. et al. 1999. "Short-course zidovudine for perinatal HIV-1 transmission in Bangkok, Thailand: A ran- domised controlled trial," Lancet 353: 773-780.

Taha, P. et al. 1997. "Effect of cleansing the birth canal with antiseptic solution on maternal and newborn morbidity and mortality in Malawi: Clinical trial" British Medical Journal 315(7102): 216-219.

UNAIDS. 1999. Large Scale Implementation for Prevention of Mother-to-Child Transmission of HIV: Issues for Southeast Asia and the Pacific, Technical Update no. 1. Geneva: UNAIDS. . 2002. Report on the Global HIVIAIDS Epidemic 2002. Geneva: UNAIDS.

WHO. 1999. HIV in Pregnancy: A Review. Geneva: WHO.

- 2001. Effect of Breastfeeding on Mortality Among HIV-Infected Women, WHO Statement no. 7. Geneva: WHO. . 2002a. New Data on the Prevention of Mother-to-Child Transmission of HIV and Their Policy Implications, WHO Technical Consultation on Behalf of the UNFPA/UNICEF/WHO/ UNAIDS Inter-Agency Task Team on Mother-toChild Transmission of HIV. Geneva: WHO. - 2002b. Breastfeeding and Replacement Feeding Practices in the Context of Mother-to-Child Transmission of HIV: An Assessment Tool for Research. Geneva: WHO.

WHO/UNAIDS/UNICEF. 2000. "HIV and infant feeding counselling: A training course," document $\mathrm{WHO} / \mathrm{FCH} /$ CAH/00.2. Geneva: WHO.

Wiktor, S.Z. et al. 1999. "Short-course oral zidovudine for prevention of mother-tochild transmission of HIV-1 in Abidjan, Côte d'Ivoire: A randomized trial," Lancet 353(9155): 781-785. 


\section{Chapter 5}

\section{HIV Prevention Through Management of Reproductive Tract Infections}

Reproductive tract infections (RTIs) comprise three types of infections that affect the reproductive tract: sexually transmitted infections (STIs) caused by viruses (such as herpes simplex virus, human papillomavirus, and HIV), bacteria (such as chlamydia, gonorrhea, syphilis, and chancroid) or other microorganisms (such as trichomoniasis) that are transmitted through sexual activity with an infected partner; endogenous infections that result from an overgrowth of organisms normally present in the vagina (bacterial vaginosis and yeast infection); and iatrogenic infections caused by the introduction of microorganisms into the reproductive tract through a medical procedure (Population Council 2001). ${ }^{10}$ Vaginal infection is most commonly caused by endogenous infections but can also be caused by certain STIs (such as trichomoniasis). Cervical infection is most commonly caused by STIs (such as chlamydia and gonorrhea), but can be caused by a variety of pathogens. Both vaginal and cervical infections can spread to the upper reproductive tract, but cervical infections are more prone to such progression. Transcervical procedures (such as menstrual regulation, abortion, and the insertion of intrauterine devices) may facilitate infection of the upper reproductive tract.

Sexually transmitted infections can cause a wide variety of symptoms (e.g., genital ulcers, genital warts, abnormal genital tract discharge, and lower abdominal pain) but are often asymptomatic, particularly in women (Holmes et al. 1999). Long-term sequelae include infertility in both men and women, cervical cancer, ectopic pregnancy, spontaneous abortion, premature rupture of membranes, premature delivery and consequent low birthweight, neonatal blindness and infection, and death. Women are more vulnerable to STIs and their sequelae than men. They are more susceptible to infection partly because semen carrying pathogens stays in the vagina for some time after sex, and partly because their reproductive tract consists of large surface areas that can be exposed to infection. In addition, women seek care less often, or delay seeking care, because their infections are likely to be asymptomatic, they may interpret symptoms such as vaginal discharge as "normal," or they do not have access to treatment services. The social, psychological, and economic consequences of STIs are often devastating (Dallabetta et al. 1996). While infections caused by bacterial and protozoal agents have been curable by appropriate antibiotics and chemotherapeutic agents for more than 40 years, at present viral infections cannot be cured.

According to World Health Organization (WHO) estimates, there are over 340 million new cases of curable STIs each year

10 For clarity, we use the term "RTI" only when referring to both STIs and endogenous or iatrogenic infections. Otherwise, we use the term STI. 


\section{IMPROVING STI TREATMENT IN PRIMARY HEALTH CARE CLINICS}

A program in Mwanza, Tanzania set out to prove that STI treatment reduces transmission of HIV (Grosskurth et al. 2000, 1995). It did so by improving primary health care services so that they provided effective syndromic management of STIs. Because the program required no new staff or infrastructure, it was highly cost-effective. Primary health care workers at rural clinics and dispensaries were trained to recognize common RTI syndromes and treat them appropriately. The training was brief-lasting about three weeks — and involved practical experience in an STI clinic and role-playing, with little emphasis on the etiologies of the various syndromes. Each patient was examined and a history taken; the patient was then treated and offered condoms and advised how to use them. Patients were also given notification cards to distribute to their partners, advising them to come to the clinic for treatment. Partners who responded were given counseling and treatment, whether or not they exhibited symptoms of RTIs. About twice a year, on market days, health educators circulated throughout the community with large posters and talked to passers-by about the importance of seeking treatment for RTIs. The program was evaluated over two years, during which time 98 percent of cases that were followed up had been cured. The effective treatment of STIs in the community seemed to reduce the spread of HIV as well, as HIV incidence in the general population fell by approximately 40 percent, compared to the incidence in villages where the intervention was introduced at the end of the two-year study.

(170 million cases of trichomoniasis, 89 million cases of chlamydia, 62 million cases of gonorrhea, 12 million cases of syphilis, and 7 million cases of chancroid) (WHO/ UNAIDS 1997). The largest proportions of new infections are thought to occur in South and Southeast Asia (46 percent), followed by sub-Saharan Africa (20 percent), and Latin America and the Caribbean (11 percent).

It has been well documented that both ulcerative and nonulcerative RTIs facilitate the transmission of HIV (Wasserheit 1992). In the absence of RTIs, the risk that HIV will be transmitted during a single sexual act is quite low; but if one partner has a genital ulcer (caused by herpes, chancroid, or syphilis, for example) this risk may be increased 300-fold (Wasserheit 1992). RTIs that do not cause ulcers, such as gonorrhea or chlamydia, also increase the risk of HIV transmission, although to a lesser degree (Wasserheit 1992). Research is ongoing to determine whether bacterial vaginosiswhich is present in up to half of all women of reproductive age in many African countries-increases the risk of HIV transmission as well. RTIs increase both the infectiousness of HIV and the susceptibility of an individual to HIV infection, so that the risk of transmission is increased if either the HIVnegative partner or the HIV-positive partner has an RTI (Wasserheit 1992). Perhaps the strongest evidence for the association between the presence of STIs and HIV incidence is that after the improvement of STI treatment services in primary health care clinics in northern Tanzania, HIV incidence in the general population fell by approximately 40 percent (Grosskurth et al. 1995).

The challenges of RTI prevention, diagnosis, and treatment in resource-poor settings

An important obstacle to slowing the HIV/AIDS epidemic is the large number of undiagnosed, untreated, or ineffectively treated RTIs worldwide (Buve 2001; Paxton et al. 1998). First, many women and some men who are infected show no symptoms or do not recognize them, even in settings with high RTI prevalence. For example, in the Rakai Project in Uganda, ${ }^{11} 80$ percent of all infected people were asymptomatic (Paxton et al. 1998). Second, many people—especially women-who know or suspect that they are infected never seek care. In the Rakai Project, only 56 percent of infected people with symptoms sought care (Paxton et al. 1998). Effective RTI management has traditionally not been offered as part of publicsector primary health care, family planning, 
or maternal and child health $(\mathrm{MCH})$ services, and stand-alone public-sector STI clinics are often remotely located and stigmatized. Men therefore often seek STI services from private physicians, but women usually cannot afford the fees charged for private care. Third, when people do seek services, they may not be adequately diagnosed or treated, or they may experience treatment failure. In the Rakai Project, 33 percent of all infected, symptomatic people who sought care received ineffective treatment (Paxton et al. 1998). For example, existing laboratory tests for RTIs can be expensive or technically complicated, are often only available in major urban areas, or are inappropriate for screening larger populations. In some cases, the appropriate first-line drugs for treatment-or second-line drugs in case of resistance-may not be available. Finally, sexual partners of people who are diagnosed with an RTI may not be notified. In the Rakai Project, only 5.7 percent of partners were notified (Paxton et al. 1998).

\section{Interventions to reduce the prevalence} and incidence of RTIs

Recommendations aimed at Ministry of Health officials in resource-poor countries on the prevention and control of sexually transmitted infections have been published (WHO/UNAIDS 1997). Because so many STIs are undiagnosed or cannot be treated, primary prevention of their transmission is crucial. Primary prevention strategies include reducing exposure to sexually transmitted disease pathogens by promoting sexual abstinence and a delay in initiating intercourse, reducing the number of sexual partners, and promoting mutually monogamous relationships. The efficiency of transmission can be reduced by encouraging and enabling safer sex practices, such as nonpenetrative sex and use of condoms (see Chapter 2). Secondary prevention, consisting of shortening the duration of infectivity by identifying and promptly treating infected people, should include the promotion of health care-seeking behavior (such as mass media campaigns to increase community awareness and reduce stigma); screening to identify asymptomatic infections; effective, accessible, and acceptable clinical services; and support and counseling services, including partner notification.

Integration of RTI services into other reproductive health services

Integrating RTI services into other reproductive health services (such as family planning and $\mathrm{MCH}$ services) is one potential way to reach more people and improve access to RTI care. However, program designers and service providers typically face a number of challenges in their efforts to integrate services (WHO 1999). While the prevalence of endogenous RTIs among women and STIs among women and men are considered to be "epidemic" overall, their regional or national prevalence varies widely. This makes it difficult to mount "one-size-fits-all" services in every setting. A recent review of the literature concluded that integration works only if routine consultations are reoriented toward protection against the dual risks of unintended pregnancy and infection, and involve clients in deciding the outcome of the consultation (i.e., a client-centered approach), steps that would require a substantial adjustment by service providers (Askew and Maggwa 2002). Furthermore, managing RTIs effectively is a difficult task and may overburden underfunded health services that are not already offering clinical services. Lastly, many attempts to integrate RTI services into other services have been unsuccessful because of poorly maintained facilities, inadequately trained and equipped staff, and inconsistent drug supplies (Mayhew et al. 2000). With the possible exception of parts of sub-Saharan Africa, rates of infection among women attending family planning and $\mathrm{MCH}$ clinics could well be much lower than in other 
population groups, thus casting doubt on one

of the most common rationales for integrating

RTI services within these settings. While

awareness-raising, counseling, and health education about RTIs are recommended in all sit-

uations and circumstances, an assessment of

overall rates of RTIs among women attending

antenatal clinics should precede the introduc-

tion of clinical services into family planning

or MCH settings (WHO 1999).

While these concerns are indeed impor-

tant, the overall benefits of integration of services often far outweigh the drawbacks.

Since the 1990s, the integration of RTI services with other health services has been encouraged in many places, such as areas with widespread HIV epidemics. By integrating these services into other services, a larger number of people can be educated and screened for RTIs, and access to RTI care can be greatly improved, especially for women.

\section{RTIs and family planning}

As discussed in more detail in Chapter 2, many contraceptive methods that are effective in preventing pregnancy do not prevent RTIs. Male and female condoms offer good protection against most STIs, and research is ongoing to determine whether diaphragms also offer some protection. Diaphragms, however, are associated with increased susceptibility to endogenous and urinary tract infections.

Hormonal contraceptive methods do not protect women from STIs, and research is ongoing to assess whether they modify risk for HIV. Intrauterine devices (IUDs) and sterilization also do not offer protection against STIs, nor do they significantly increase risk of infection, although IUD insertion and surgical sterilization are both associated with some increased risk for iatrogenic infections. IUD insertion and surgical sterilization can also exacerbate existing infections, so it is impor- tant to ensure that women undergoing these procedures are not already infected. ${ }^{12}$

The syndromic approach to RTI diagnosis and treatment

There are at least three ways to diagnose and make treatment decisions with regard to symptomatic RTIs: laboratory testing, clinical diagnosis, and syndromic management. Laboratory testing is clearly the most accurate method of diagnosing RTIs, but most laboratory procedures require sophisticated and expensive equipment, well-trained technicians, and temperature-controlled storage for specimens and reagents. For example, an accurate test for gonorrhea may cost as much as US\$15, or may require culture under specific conditions. Clinical diagnosis of many RTIs is extremely difficult and often impossible-few doctors in developing or developed countries can make accurate diagnoses.

Because of the limitations of both laboratory and clinical diagnosis, WHO recommends the use of syndromic management for the diagnosis and treatment of the most common infections, even when laboratory services are remote and budgets are tight (Population Council 2001; WHO 2001).

Syndromic case management is based on classifying the main causative agents that give rise to a particular syndrome (genital ulcers in men and women, urethral discharge in men, vaginal discharge in women, and lower abdominal pain in women) using a combination of symptoms reported by the client and signs observed by the clinician. It then uses flowcharts that help the health care provider reach a diagnosis and decide on treatment. The recommended treatment is effective for all the pathogens that could have caused the identified syndrome. The syndromic approach, sometimes in combination with risk scoring (see below), has been tested and implemented in a variety of countries. It was 
found to be effective for genital ulcers in men and women and urethral discharge in men, but less effective for vaginal discharge (particularly the management of cervical infections) and lower abdominal pain in women (Sloan et al. 2000; Dallabetta et al. 1998, 1996). The problem with using vaginal discharge as a symptom is that it can be caused by a wide range of organisms (see table, "Major RTI syndromes and likely causes"). Some conditions, such as bacterial vaginosis, are extremely difficult to cure. In addition, many women experience vaginal discharge even in the absence of any type of infection. Syndromic management will inevitably miss all infections in asymptomatic women and may lead to the treatment of some clients who do not actually have an STI.

Risk assessments are questions asked of clients by service providers that are used to substantiate clients' complaints (e.g., vaginal discharge), to screen for STIs in clients not aware of symptoms (e.g., prior to providing contraceptives), or to determine further counseling needs (Fox et al. 1995). WHO recommends that they be part of standard family planning and reproductive health practice, whether services are formally integrated or not (WHO 1999). Systematic risk assessments aimed at generating a risk score have also been used, for example to improve the performance of syndromic management of RTIs. Research indicates that risk assessment or risk scoring alone, without any other method of diagnosis (such as a pelvic exam), is not accurate in predicting the presence of an STI, especially in distinguishing between vaginal and cervical infections (the latter being more serious). Unfortunately, the combination of risk assessment or risk scoring with clinical examinations has yielded little additional accuracy (WHO 1999).

Overtreatment is of increasing concern, as the overuse of antibiotics leads to drugresistant bacterial strains, as well as to the

\section{MAJOR RTI SYNDROMES AND LIKELY CAUSESa}

\begin{tabular}{|c|c|}
\hline Syndrome & Likely causes \\
\hline Urethral discharge (male) & $\begin{array}{l}\text { Gonorrhea, chlamydia, } \\
\text { trichomoniasis }\end{array}$ \\
\hline Genital ulcer (male and female) & $\begin{array}{l}\text { Syphilis, chancroid, granuloma } \\
\text { inguinale, genital herpes, }{ }^{b} \\
\text { lymphogranuloma venereum }\end{array}$ \\
\hline Inguinal bubo (male and female) & $\begin{array}{l}\text { Lymphogranuloma venereum, } \\
\text { chancroid }\end{array}$ \\
\hline Scrotal swelling (male) & Gonorrhea, chlamydia \\
\hline Vaginal discharge (female) & $\begin{array}{l}\text { In many cases, no discernible } \\
\text { cause; however, trichomoniasis, } \\
\text { yeast infection, and/or bacterial } \\
\text { vaginosis are possible causes; } \\
\text { some vaginal discharge may be } \\
\text { cervical discharge caused by } \\
\text { gonorrhea or chlamydia }\end{array}$ \\
\hline Cervical discharge (female) & Chlamydia and/or gonorrhea \\
\hline Lower abdominal pain (female) & $\begin{array}{l}\text { Pelvic inflammatory disease } \\
\text { caused by gonorrhea or chlamydia }\end{array}$ \\
\hline \multicolumn{2}{|c|}{$\begin{array}{l}\text { a Regular monitoring by a reference laboratory should accompany all syndromic } \\
\text { management programs; small studies of a few hundred patients can determine } \\
\text { the most prevalent microbes and patterns of drug resistance. }\end{array}$} \\
\hline $\begin{array}{l}\text { b Genital herpes is a growing problen } \\
\text { cure for herpes, but acyclovir can red } \\
\text { of official syndromic management pro }\end{array}$ & $\begin{array}{l}\text { pecially in sub-Saharan Africa; there is no } \\
\text { symptoms. Although acyclovir is not part } \\
\text { ols, it may be added in the near future. }\end{array}$ \\
\hline
\end{tabular}

development of conditions (such as yeast infections) that result from antibiotic use in the absence of bacterial infection. In addition, the potential emotional consequences of overtreatment should not be overlooked. If a woman is treated for an infection she does not have, telling her husband might cause distress that could have been avoided.

Decisions about how to manage RTIs will depend largely on the local situation. Before adopting a particular policy, program designers should make every effort to determine the prevalence of different STIs and drug-resistant strains in the area. Reference labs might conduct a small-scale study to find the prevalence of different RTIs in a sample of family planning or $\mathrm{MCH}$ clients, or they could rely on the results of studies 


\section{SYPHILIS SCREENING IN PREGNANCY}

U $\mathrm{p}$ to 15 percent of women in some developing countries have active syphilis, which may cause rashes, headaches, and in severe cases may lead to bone deformities, mental illness, and death. Around half of babies born to infected women will either fail to survive or will be born prematurely or with low birthweight. A small number of these infants develop congenital syphilis, which, like the adult version of the disease, causes skin rashes, bone deformities, and mental disabilities (Holmes et al. 1999).

It costs less than US $\$ 0.50$ to diagnose and cure syphilis, and antenatal clinics in developing countries are an ideal place to provide infected women and their sexual partners with counseling, testing, and treatment. However, a recent survey of syphilis screening programs in Africa found that 1.6 million cases in pregnant women went untreated every year. This number included more than a million women who attended antenatal clinics but were not screened. Improving syphilis screening programs in antenatal clinics is therefore a priority for $\mathrm{MCH}$ staff.

During the 1980s, a syphilis screening program in Zambia demonstrated how effective such programs can be (Hira et al. 1990). At the time, around 13 percent of pregnant Zambian women were estimated to be infected with syphilis, accounting for 20-30 percent of the total perinatal mortality rate of 50 per 1,000 births (Hira et al. 1990). While syphilis screening and treatment were supposed to be part of the national antenatal care program, in practice the system worked poorly. Most women made their first antenatal visit late in pregnancy, by which time syphilis treatment is far less effective in preventing severe birth outcomes. Even when women attended early in pregnancy, very few were actually screened for syphilis, and those who were diagnosed with syphilis were seldom given proper treatment. Their sexual partners were rarely notified and urged to seek treatment.

Doctors at the University Teaching Hospital in Lusaka were determined to improve the antenatal syphilis screening program. They began by employing outreach workers to visit urban shantytowns and encourage pregnant women to come to the clinic early in their pregnancies for antenatal care. They ensured that syphilis screening at these clinics was carried out properly and that there were adequate supplies of drugs. Infected women were given cards to give to their sexual partners, advising them to come to the clinic for treatment as well. After one year, four times as many women attended the antenatal clinics early in pregnancy as before, and among women with syphilis the proportion of adverse pregnancy outcomes was reduced dramatically-from 72 to 28 percent.

While the project was successful, there was room for improvement. More than half of pregnant women failed to seek antenatal care before the 16th week of their pregnancy, after which it is much more difficult to prevent adverse birth outcomes. More-intensive health education within the community over a longer period may be necessary to encourage more women to attend antenatal clinics earlier. that have already been carried out in the area by the Ministry of Health or independent research groups. The prevalence of HIV and RTIs may vary considerably from place to place, even within a single country.

Like rapid tests for HIV, rapid tests for other RTIs have the potential to greatly simplify case finding and case management (Mabey et al. 2001). Rapid tests for a variety of RTIs are currently being developed and/or evaluated, with rapid tests for gonorrhea and chlamydia receiving highest priority. It is likely that they will be integrated into reproductive health services in the near future.

Furthermore, research is ongoing to evaluate alternative methods of specimen collection in women that do not require pelvic examinations, such as self-administered swabs and tampons, and urine. These alternative methods may simplify the logistics of RTI screening in resource-poor settings, and be more acceptable to women.

Partner notification, contact tracing, and gender-related violence

The primary purpose of partner notification is to prevent a treated client from becoming re-infected and to prevent transmission to others. Partner notification can be achieved by asking index cases to notify their partner(s) themselves, or by having public 
health officials undertake contact tracing (Mathews et al. 2002; Adler et al. 1998). In some settings, index cases are given an additional course of treatment for each partner and are asked to hand these to their partner(s) themselves. Partner notification is voluntary and is sometimes greatly complicated by the possibility of gender-related violence directed against women. Some programs offer to notify the partners of women who prefer not to do it themselves, but disclosure through a provider referral system must also be done with great caution in order to avoid putting women at risk of violence. One project in Tanzania used outreach workers to notify the partners of women who tested positive for HIV or other STIs, but this part of the project had to be abandoned because many of the outreach workers came from the same communities as the clients, and they felt awkward talking about sexual risk and disease with the clients' partners. In Zimbabwe, almost 30 percent of people attending an STI clinic gave false names and addresses when asked who their most recent sexual partners were (Winfield and Latif 1985). Taking these realities into account, service providers should allow clients to decide whether and how a partner or partners should be notified. While partner notification is theoretically an important public health intervention, in practice disclosure may not always produce its intended consequence-namely STI diagnosis and treatment for the partner.

\section{References}

Adler, M. et al. 1998. Sexual Health and Health Care: Sexually Transmitted Infections-Guidelines for Prevention and Treatment, Health and Population Occasional Paper. London: Department for International Development.

Askew, Ian and Ndugga Baker Maggwa. 2002. "Integration of STI prevention

\section{CHALLENGES FACING RTI PROGRAMS IN DEVELOPING COUNTRIES}

T $n$ many clinical settings in developing countries, the shortage of doc-

1 tors means that trained nurses deliver the majority of routine health care services. In order for RTI management programs to run smoothly in family planning clinics, nurses must be permitted and trained to dispense the drugs to treat these diseases. In Kenya, researchers from the African Population and Health Research Center found that the relevant legislation governing the dispensing of pharmaceuticals did not clarify whether nurses were allowed to do this, and prescription of RTI drugs was, in any event, not part of nurses' training. Revising the laws to make it easier for nurses to manage RTIs was complicated by the fact that some doctors saw this as an infringement of their own authority and responsibilities.

In Botswana, Kenya, Tanzania, and Uganda, the Population Council also found that many RTI services were dispensing the wrong drugs. Often this was because treatment guidelines had not been updated or, if they had been, health workers were not aware of them. Sometimes the most effective drugs were out of stock or were not on "Essential Drugs" lists. In Tanzania and Uganda, RTI programs were found to be severely underfunded and could not afford to dispense the most effective medications.

Source: Miller et al. 1998.

\section{REQUIREMENTS FOR AN EFFECTIVE FAMILY PLANNING/RTI PREVENTION PROGRAM}

- Reliable running water and electricity for sterilization and other surgical procedures;

- Contraceptives, including male and female condoms;

- Counselors trained in syndromic management of RTIs and in conducting risk assessments;

- Information, education, and communication materials dealing with HIV/RTI prevention, including leaflets, comic books, and posters;

- Drugs for STIs;

- HIV test kits;

- Information about a referral lab for RTI diagnosis (or, eventually, rapid diagnostics onsite); and

- Equipment for pelvic exams.

and management with family planning and antenatal care in sub-Saharan

Africa: What more do we need to know?" International Family Planning Perspectives 28(2): 77-86. 
Buve, A. 2001. "How many patients with a sexually transmitted infection are cured by health services? A study from Mwanza region, Tanzania," Tropical Medicine and International Health 6(12): 971-979.

Dallabetta, G.A., A.C. Gerbase, and K.K. Holmes. 1998. "Problems, solutions and challenges in syndromic management of sexually transmitted diseases," Sexually Transmitted Infections 74(suppl 1): S1-S11.

Dallabetta, G.A., M. Laga, and P. Lamptey. 1996. Control of Sexually Transmitted Diseases: A Handbook for the Design and Management of Programs. Arlington, VA: AIDSCAP/Family Health International.

Fox, L.J. et al. 1995. "Improving reproductive health: Integrating STD and contraceptive services," Journal of the American Medical Women's Association 50: 129-136.

Grosskurth, H. et al. 1995. "Impact of improved treatment of sexually transmitted diseases on HIV infection in rural Tanzania: Randomised controlled trial," Lancet 346: 530-536.

- 2000. "Operational performance of an STD control programme in Mwanza Region, Tanzania," Sexually Transmitted Infections 76: 426-436.

Hira, S.K. et al. 1990. "Syphilis intervention in pregnancy: Zambia demonstration project," Genitourinary Medicine 66(3): 159-164.

Holmes, K.K. et al. 1999. Sexually Transmitted Diseases, ed. 3. New York: McGraw-Hill.

Mabey, D., R.W. Peeling, and M.D. Perkins. 2001. "Rapid and simple point of care diagnostics for STIs," Sexually Transmitted Infections 77: 397-401.

Mathews, C. et al. 2002. "A systematic review of strategies for partner notification for sexually transmitted diseases, including HIV/AIDS," International Journal of STD and AIDS 13(5): 285-300.
Mayhew, S.H. et al. 2000. "Implementing the integration of component services for reproductive health," Studies in Family Planning 31(2): 151-162.

Miller, K., H. Jones, and M.C. Horn. 1998. "Indicators of readiness and quality: Basic findings," in K. Miller et al. (eds.), Clinic-Based Family Planning and Reproductive Health Services in Africa: Findings from Situation Analysis Studies. New York: Population Council, pp. 29-85.

Paxton, L.A. et al. 1998. "Community-based study of treatment seeking among subjects with symptoms of sexually transmitted disease in rural Uganda," British Medical Journal 317(7173): 1630-1631.

Population Council. 2001. Reproductive Tract Infection Fact Sheets. New York: Population Council, www. popcouncil.org/rhfp/rti_fact_sheets/ index.html.

Sloan, N.L. et al. 2000. "Screening and syndromic approaches to identify gonorrhea and chlamydial infection among women," Studies in Family Planning 31(1): 55-68.

Wasserheit, Judith N. 1992. "Epidemiological synergy: Interrelationships between human immunodeficiency virus infection and other sexually transmitted diseases," Sexually Transmitted Diseases 19(2): 61-77.

WHO. 1999. Integrating STI Management into Family Planning Services: What Are the Benefits? Geneva: WHO. 2001. Guidelines for the Management of STIs, document WHO/HIV_AIDS/2001.01, WHO/RHR/01.10. Geneva: WHO. WHO/UNAIDS. 1997. Sexually Transmitted Diseases: Policies and Principles for Prevention and Care, Best Practice Collection. Geneva: WHO/UNAIDS. Winfield, S. and A.S. Latif. 1985. "Tracing contacts of sexually transmitted diseases in a developing country," Sexually Transmitted Diseases 12(1): 5-7. 


\section{Chapter 6}

\section{HIV Prevention Among Refugees and Other Displaced Persons}

Refugee agencies have long recognized the health needs of people displaced by war and natural disasters, including clean water, sanitation, and vaccination. Until the 1990s,

HIV/STI prevention was not seen as a priority in emergencies; however, it is now known that displaced people are at great risk of HIV. If the refugees come from regions where HIV and STIs are already common, there is an even greater danger that the dislocation, chaos, poverty, and boredom of refugee life-in addition to the inadequate health care coverage in general and poor quality of HIV prevention, care, and support programs - will increase the spread of these infections. Because HIV surveillance is not a priority in emergencies, there are few reliable statistics on the incidence and prevalence of HIV among displaced persons. Even so, the incidence of rape in emergencies is believed to be very high, and the poverty and social disruption of war are believed to make commercial sex more common.

While not all cases of HIV infection during and after emergencies are believed to be the result of rape and violence, health workers who assist refugee and internally displaced populations should consider ways to reduce violence, in addition to carrying out more routine HIV prevention activities. The causes of sexual violence during conflict are not well understood. Factors that are believed to contribute to increased rape and abuse of women and young people before, during, and after emergencies include the conditions of social disassociation and uncertainty of displacement and demobilization, or social norms that translate into disregard for the rights of women and children, heightened alcohol and drug abuse, and the disintegration of traditional social sanctions that might otherwise discourage such behavior. In addition, sexual violence in war and afterward often has a political motive, so that women from one ethnic group or political faction are targeted by men from the opposing side. This was the case during the wars in Bosnia and Rwanda, for example (Peterson and Runyan 1999; Nikolić-Ristanović 1996). During periods of conflict, men gain greater control over goods and services that women and children need. Soldiers and camp leaders may demand sexual favors in return for such goods as food and access to water, and bandits and border guards may see fleeing women and children as easy targets.

Once an emergency situation is reasonably stable, nongovernmental organizations (NGOs) working in refugee camps and with other displaced groups should be encouraged to carry out a comprehensive HIV prevention campaign. Because of the unique circumstances, contingencies, and resource constraints associated with the management of refugees and internally displaced people, there are several redundant elements of a comprehensive HIV/AIDS intervention program that are critical. 


\section{HIV PREVENTION FOR REFUGEES: A CASE STUDY FROM NGARA, TANZANIA}

$\mathrm{I}_{\mathrm{r}}^{\mathrm{n}}$

n 1994 approximately 300,000 refugees crossed into

Tanzania from Rwanda after the war and genocide there.

The refugees settled in three camps in Ngara. It was not known how many refugees were HIV-positive at the time, but there were concerns that an epidemic might occur, both in the refugee community and among the impoverished local population. The refugees greatly swelled the population of the local area, and before long migrant traders from other parts of Tanzania established an informal market outside the camps. Sex workers also established premises around the camps.

A consortium of 13 NGOs, coordinated by the U.N. High Commissioner for Refugees (UNHCR) and with technical guidance from the African Medical and Research Foundation and funding from UNFPA and UNHCR, quickly established an HIV/STI prevention program in the Ngara camps (Mayaud et al. 1997). As the program was being established, the team conducted rapid surveys of a few hundred refugees, both men and women, to determine existing rates of RTIs as well as knowledge, attitudes, and practices regarding sex. The researchers were unable to measure rates of HIV infection because some of the NGOs expressed concern that if the information became widely known, it might further stigmatize people in the camps; but researchers did determine that rates of certain RTIs, especially vaginal infections, were quite high.

They also identified and helped strengthen local resources in the camps and the surrounding communities for HIV and RTI prevention and treatment. At the same time, the teams organized a condom marketing campaign and trained doctors and nurses at outpatient clinics to use syndromic management to diagnose and treat RTIs (see Chapter 5). In addition, a syphilis screening program for pregnant women was established in antenatal clinics. Program staff trained members of the refugee community to work as peer educators in the promotion of safer sex and condom use among the clients of bars and brothels. Some of these outreach workers were themselves sex workers or bar owners. Teams of health educators from the refugee community were given large posters with cartoons depicting scenes from an STI clinic or a romantic encounter. The teams set up the posters in places where people gathered (e.g., in the informal markets), and the posters attracted attention. After a small crowd had gathered, health educators would discuss the scenes in the cartoons and convey important messages such as what HIV is, how it is and is not transmitted, and how people can protect themselves from HIV.

Even though HIV infection rates were not measured, there were many indications that the program was successful in limiting the spread of HIV and STIs. As soon as people realized that improved services were available to treat STIs, the caseload at health posts rose nearly tenfold. The contacts of about a third of these cases were treated as well-a reasonably high number considering the difficulties surrounding partner notification (see Chapter 5). The refugees remained in Tanzania for two years, during which time rates of syphilis, urethritis, and cervical and vaginal infections fell by at least 50 percent. At the same time, however, there was evidence that commercial sex and sexual violence continued to occur. After the refugees returned to Rwanda in 1996, an HIV-prevalence survey was carried out among returnees who had been housed in camps in Burundi, Tanzania, and Zaire, as well as among the internally displaced. The results indicated that returnees from the Tanzanian camps had lower HIV infection rates than those who had been displaced elsewhere.

\section{Basic HIV Prevention Services for Refugees and Internally Displaced Persons}

1. Camp design. Health workers should bear in mind that the design of camps can provide an environment that may be conducive to sexual violence. For example, isolated latrines and sources of water and firewood can make women and children vulnerable to coercion, sexual abuse, or rape. In addition, the lack of privacy characteristic of camps can also foster the necessity for quickness and lack of intimacy in sexual interactions. This in turn can discourage the negotiation and use of condoms or other risk-reduction behaviors. 
2. Rapid assessments. Small surveys to determine RTI infection rates and patterns of antibiotic resistance can greatly aid the design of interventions aimed at reducing the prevalence of these infections, as well as HIV (for more information, see Chapter 5 and box).

\section{Dedicated reproductive health services.}

Often reproductive health services for displaced people, if they exist at all, are combined with services to treat conflict-related casualties and other health problems. However, specialized reproductive health services have the advantage of being able to focus on the special health and emotional needs of people suffering from STIs, HIV/AIDS, or the consequences of sexual abuse and rape. Such services should include treatment for STIs as well as training of health care workers in syndromic management, a system to ensure that essential drugs for the most common STIs are available, and a monitoring system to identify the most common infections and their resistance patterns. Lab services to accurately diagnose every case of infection are unlikely to be feasible in most emergency situations.

\section{HIV counseling and testing. Available} resources for HIV testing should be devoted first and foremost to ensuring the safety of blood supplies for transfusion. A voluntary counseling and testing program is a lower priority in refugee situations, but should not be ruled out if resources are available in the host county or in the country of origin. Mandatory HIV testing among refugees, with the single exception of testing blood for transfusion, is not justified.

5. Condom promotion. Male and female condoms and other contraceptives should be as widely and easily accessible as possible.

UNAIDS recommends that for a population of 10,000 displaced people, 25,000 condoms are needed every month (UNAIDS 1999). Condoms should be of high quality and should not be mishandled during shipping and distribution. It is especially important that condoms be kept out of direct sunlight and heat and away from sources of water-both of which will compromise their effectiveness.

\section{HIVIAIDS educators and counselors. A} team of HIV/AIDS educators and counselors can work both as peer educators_-advising displaced populations about sexual health risks and distributing condoms - and as an outreach referral system-locating men and women in need of reproductive health services and helping them gain access to diagnosis and treatment. HIV/AIDS educators should come from the displaced community itself, so that they know the language and customs of the people. They should then be properly trained to promote condoms and offer advice to people who think they may have an STI or who have been subject to abuse.

\section{Media campaigns. The use of con-} doms can also be promoted through educational activities and the media. Radio spots can be particularly effective for promoting condom use in emergencies because many people listen to the radio to follow political developments.

8. Counseling, care, and treatment for victims of sexual coercion and violence. In emergencies, HIV/AIDS counselors and health care workers are likely to encounter women and children who they suspect have been sexually abused. The United Nations High Commissioner for Refugees recommends that counselors be of the same sex as the suspected victim, and that counseling sessions be conducted in private (UNHCR 1995). If the victim agrees to discuss the case, he or she should be encouraged to report it to the authorities. The victim should be advised of what to expect if he or she decides to make a report to the police. Cases of domestic abuse, in particular, must be handled carefully. If a 
woman is raped, she should be offered emergency contraception to prevent pregnancy. If HIV infection is common in the area, health workers should be prepared to offer HIV prophylaxis using antiretroviral drugs. These drugs must be administered within 72 hours after the rape in order to have the greatest chance of preventing infection.

9. Support groups and work programs. Refugees often experience powerlessness, frustration, fear, anger, and boredom due to the unfamiliar and difficult conditions in which they are placed. These feelings can inflame violence, including sexual violence. It is important to reconstruct, as far as possible, the routines and social ties that have been disrupted by the emergency and to restore the self-respect of displaced persons. Toward this end, groups working with refugees advocate the formation of support groups and work programs for refugees.

\section{References}

Mayaud, P. et al. 1997. "STD rapid assessment in Rwandan refugee camps in Tanzania," Genitourinary Medicine 73(1): 33-38.

Nikolić-Ristanović, Vesna. 1996. "War and violence against women," in Jennifer Turpin and Lois Ann Lorentzen (eds.), The Gendered New World Order: Militarism, Development and the Environment. New York: Routledge, pp. 195-210.

Peterson, V. Spike and Anne Sisson Runyan. 1999. Global Gender Issues, ed. 2. Boulder: Westview Press.

UNAIDS. 1999. Guidelines for HIV Prevention in Emergency Settings. Geneva: UNAIDS.

United Nations High Commissioner for Refugees. 1995. Sexual Violence Against Refugees: Guidelines on Prevention and Response. Geneva: UNHCR. 